\title{
Causes of Increasing Aridification of the Mediterranean Region in Response to Rising Greenhouse Gases*
}

\author{
Richard Seager, Haibo liu, Naomi Henderson, Isla Simpson, Colin Kelley, Tiffany Shaw, \\ YOCHANAN KUSHNIR, AND MINGFANG TING \\ Lamont-Doherty Earth Observatory, Columbia University, Palisades, New York
}

(Manuscript received 25 July 2013, in final form 25 March 2014)

\begin{abstract}
The hydrological cycle in the Mediterranean region, as well as its change over the coming decades, is investigated using the Interim European Centre for Medium-Range Weather Forecasts Re-Analysis (ERAInterim) and phase 5 of the Coupled Model Intercomparison Project (CMIP5) historical simulations and projections of the coming decades. The Mediterranean land regions have positive precipitation minus evaporation, $P-E$, in winter and negative $P-E$ in summer. According to ERA-Interim, positive $P-E$ over land in winter is sustained by transient eddy moisture convergence and opposed by mean flow moisture divergence. Dry mean flow advection is important for opposing the transient eddy moisture flux convergence in the winter half year and the mass divergent mean flow is a prime cause of negative $P-E$ in the summer half year. These features are well reproduced in the CMIP5 ensemble. The models predict reduced $P-E$ over the Mediterranean region in the future year-round. For both land and sea, a common cause of drying is increased mean flow moisture divergence. Changes in transient eddy moisture fluxes largely act diffusively and cause drying over the sea and moistening over many land areas to the north in winter and drying over western land areas and moistening over the eastern sea in summer. Increased mean flow moisture divergence is caused by both the increase in atmospheric humidity in a region of mean flow divergence and strengthening of the mass divergence. Increased mass divergence is related to increased high pressure over the central Mediterranean in winter and over the Atlantic and northern Europe in summer, which favors subsidence and low-level divergence over the Mediterranean region.
\end{abstract}

\section{Introduction}

The Mediterranean region has given name to the Mediterranean type of climate, which is loosely defined as a subtropical to midlatitude climate with cool, damp winters; hot, dry summers; and overall semiarid conditions. In the Mediterranean region, like other Mediterranean climate zones such as California, southwest Australia, and parts of Southern Africa, water is a perennial concern. While ecosystems have evolved to deal with the semiarid climate and its seasonal cycle, people have always had to struggle to adapt to living with limited

\footnotetext{
* Lamont-Doherty Earth Observatory Contribution Number 7781.

Corresponding author address: Richard Seager, Lamont-Doherty Earth Observatory, Columbia University, 61 Route 9W, Palisades, NY 10964.

E-mail: seager@ldeo.columbia.edu
}

water. However, despite the harsh environment, the Mediterranean region was the cradle for the development of western civilizations. That this came to pass required the ancient Greeks and Romans to develop impressive works of hydraulic engineering to bring water from far afield to the growing cities where the developing civilizations were based (Chanson 2008). Even before the highly developed Greek and Roman civilizations, other societies such as the Minoan Crete and the Mycenaeans in southern Greece during the Bronze Age, developed sophisticated methods for water management and supply (Mays 2010). Going even further back into antiquity, Mediterranean people had developed ingenious methods for gathering storm runoff and funneling it toward planted trees or underground cisterns to ensure that water went to productive use (Hillel 1994). In the modern-day Mediterranean region, people continue to rely on complex systems of water supply or, in the case of much of North Africa, on mining of groundwater that is, in the long term, unsustainable (Schwartz and Ibaraki 2011). In 
the last few decades the region has shifted from an agriculture-based economy to one in which tourism is increasingly important. This shift led to major increases in living standards but also of water use (Essex et al. 2004). For some years, Mallorca, with its large tourist population, was importing water from mainland Spain to ensure an adequate supply (Essex et al. 2004). However, this was stopped in the face of mainland opposition and, soon thereafter, even a major city like Barcelona had to be relieved during the 2008 drought by tankers bearing water (http://www.guardian.co.uk/world/2008/may/14/spain. water). Clearly, water has been a defining aspect of the development of Mediterranean societies for centuries.

That situation is, according to all analyses of the situation so far, about to get worse as a consequence of human-induced climate change caused by increasing concentrations of greenhouse gases (GHGs). Over a decade ago, Cubasch et al. (2001) and Allen and Ingram (2002) published maps showing that climate models projected the Mediterranean region to undergo a more severe aridification than any other land region on Earth. The subsequent model projections performed for phases 3 and 5 of the Coupled Model Intercomparison Project (CMIP3 and CMIP5) and assessed by Intergovernmental Panel on Climate Change (IPCC) Fourth and Fifth Assessment Reports (AR4 and AR5) have confirmed these early projections (Hoerling et al. 2012; Kelley et al. 2011, 2012; Giorgi and Coppola 2007; Giorgi and Lionello 2008; Mariotti et al. 2009; Planton et al. 2012; Stocker et al. 2013). Further, it is now clear that the Mediterranean region drying is part of a general drying and poleward expansion of the subtropical dry zones (Held and Soden 2006; Previdi and Liepert 2007; Seager et al. 2010). However, it also appears that there is some additional process that is causing a regional maximization of subtropical drying in the Mediterranean region. Giorgi and Lionello (2008) attributed the future drying to development of anticyclonic conditions in the region while changes in the occurrence and intensity of Mediterranean cyclones also appear to play a role but not a simple one (Lionello and Giorgi 2007). Zappa et al. (2013) found a projected decrease in the wind intensity and number of Mediterranean winter cyclones, although precipitation intensity of the cyclones showed a modest increase (see also Harvey et al. 2012). For the observational record to date, Ziv et al. (2013) found a late-twentieth-century decrease in the number of Mediterranean cyclones and Trigo et al. (2000) attributed the concomitant drying to a related weakening of Mediterranean cyclones. However, according to Kelley et al. (2011, 2012), the latetwentieth-century drying was dominated by natural variability of the North Atlantic Oscillation (see also Hoerling et al. 2012), so this need not be the mechanism of drying in response to rising greenhouse gases. For future projections, Giorgi and Lionello (2008) stress that the drying and warming are exceedingly robust, are "present in most projections from both global and regional models, and are consistent across emission scenarios and future time slices" (p. 102).

Despite the Mediterranean region being a climate change "hot spot" (Giorgi 2006) and drought being a continually reoccurring challenge (Iglesias et al. 2007), the physical mechanisms of aridification in the region remain inadequately known. Here we seek to improve knowledge in this regard by examining the moisture budgets of the most recent climate model simulations performed for CMIP5 and IPCC AR5. We will examine the climatological budget in the historical simulations and compare that against the budget within the Interim European Centre for Medium-Range Weather Forecasts (ECMWF) Re-Analysis (ERA-Interim), to assess the ability of the models to represent key features of Mediterranean region hydroclimate. We will then examine the model projections of future changes in the moisture budget and relate these to changes in atmospheric specific humidity and mean and transient circulation. This will provide a clearer understanding than has been available to date of what thermodynamical and dynamical mechanisms are responsible for Mediterranean region drying. What we will not do is analyze why the dynamical changes that are responsible occur. That matter is the topic of follow-on work (Simpson et al. 2014).

\section{Reanalyses and CMIP5 model data}

The reference for the Mediterranean region moisture budget is ERA-Interim, which covers 1979-present (Berrisford et al. 2011b,a; Dee et al. 2011) and is the latest of the ECMWF reanalyses. ERA-Interim assimilates cloud and rain-affected satellite irradiances and has a greatly improved representation of the hydrological cycle relative to its precursor, the 40-yr ECMWF Re-Analysis (ERA-40), which makes it good for our purpose. ERA-Interim is based on an atmospheric model and reanalysis system with 60 levels in the vertical with a top level at $0.1 \mathrm{mb}$; a T255 spherical harmonic representation; and, for surface and grid point fields, a reduced Gaussian grid with a horizontal grid spacing of about 79-km spacing (Berrisford et al. 2011b). However, the moisture budget calculations used here were performed on data that were archived by ECMWF on a regular $1.5^{\circ}$ grid with 37 model levels and at 6 hourly resolution. All calculations were performed as in Seager and Henderson (2013, hereafter SH), which provides a thorough analysis of errors introduced by choice of numerical methods and temporal and spatial resolution. 
For the CMIP5 models (Taylor et al. 2012) we analyzed the historical simulations and the future projections using the representative concentration pathway 8.5 (RCP8.5) emissions scenario (Riahi et al. 2011). The $\mathrm{RCP} 8.5$ scenario is the high end member of the scenarios simulated and was chosen to reflect the current lack of any international action to limit greenhouse gas emissions. We used all simulations of all models that at the time the study began provided specific humidity and winds at adequate vertical resolution, with daily resolution and for the time period of interest. This allowed 15 models: details of which are provided in Table 1 . Altogether, 57 simulations were analyzed for the historical period and 43 were analyzed for the future period. Moisture budgets were computed within each model simulation, before computing an ensemble mean for each model and finally the multimodel ensemble. To create the ensemble, model data were regridded to a common $1^{\circ} \times$ $1^{\circ}$ grid. Identical methods were used for the models as for ERA-Interim and are exactly as detailed in SH. The only exception is that 6 hourly data were used for ERAInterim and daily mean data were used for the models. This choice was made based on data availability.

Our interest is in the near-term future over which adaptation planning in, for example, water resources might occur. Hence, for the future we examine the 202140 period. This is compared to the 1979-2005 period, which is the overlapping period of the ERA-Interim and the CMIP5 historical simulations.

\section{Moisture budget analysis methods}

The analysis methods follow SH and hence will only be briefly described here. The CMIP5 data archive most readily provides model data on pressure levels rather than the model native vertical grid; hence, we will work in pressure coordinates here. The steady-state moisture budget in pressure coordinates is

$$
P-E=-\frac{1}{g \rho_{w}} \nabla \cdot \int_{0}^{p_{s}} \mathbf{u} q d p,
$$

where $P$ is precipitation, $E$ is evaporation, $g$ is the acceleration due to gravity, $\rho_{w}$ is the density of water, $p$ is pressure and $p_{s}$ is its surface value, $q$ is specific humidity, and $\mathbf{u}$ is the vector horizontal velocity. Here and in the following, the notation follows that of $\mathrm{SH}$ and of Seager et al. (2012). The vertical integral is actually done as a sum over pressure levels so Eq. (1) is replaced with

$$
P-E=-\frac{1}{g \rho_{w}} \nabla \cdot \sum_{k=1}^{K} \mathbf{u}_{k} q_{k} d p_{k},
$$

where $k$ refers to vertical level of which there are $K$ total and $d p_{k}$ is the pressure thickness of each level with the lowest level extending to $p_{s}$.

To determine the climatological budget we divide all quantities up into monthly means (represented by overbars), departures from monthly means (represented by primes), and climatological monthly means (represented by double overbars). Then Eq. (2) can be rewritten as

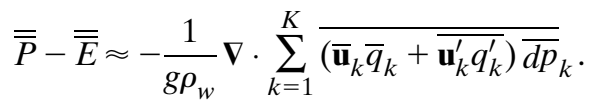

Here, the first term on the right is the moisture convergence by the mean flow and the second term is the moisture convergence by the submonthly transient eddies. The approximation comes from ignoring terms involving $d p_{k}^{\prime}$, an acceptable simplification (see $\mathrm{SH}$ ).

We will be interested in breaking down the mean flow contribution further into terms related to mass divergence and advection. In this case the divergence operator has to be taken inside the vertical summation, which introduces a surface term,

$$
\begin{aligned}
\overline{\bar{P}}-\overline{\bar{E}}= & -\frac{1}{g \rho_{w}}\left[\sum_{k=1}^{K}{\left.\overline{\left(\overline{\mathbf{u}}_{k} \cdot \nabla\right.} \bar{q}_{k}+\bar{q}_{k} \boldsymbol{\nabla} \cdot \overline{\mathbf{u}}_{k}\right) \overline{d p}_{k}}\right. \\
& \left.+\nabla \cdot \sum_{k=1}^{K} \overline{\overline{\mathbf{u}}_{k}^{\prime} q_{k}^{\prime}} \overline{d p}_{k}\right]-\frac{1}{g \rho_{w}} \overline{\overline{q_{s} \mathbf{u}_{s} \cdot \nabla p_{s}}} .
\end{aligned}
$$

To look at climate change, we introduce

$$
\Delta(\cdot)=(\cdot)_{21}-(\cdot)_{20}
$$

to represent a difference between twenty-first-century (subscript "21") and twentieth-century (subscript "20") quantities. Substituting into Eqs. (3) and (4), we get

$$
\begin{aligned}
& \Delta \overline{\bar{P}}-\Delta \overline{\bar{E}}=-\frac{1}{g \rho_{w}} \nabla \cdot \sum_{k=1}^{K} \Delta\left(\overline{\overline{\mathbf{u}}}_{k} \bar{q}_{k} \overline{\overline{d p}}_{k}\right)-\frac{1}{g \rho_{w}} \nabla \cdot \sum_{k=1}^{K} \Delta\left({\overline{\overline{\mathbf{u}_{k}^{\prime} q_{k}^{\prime}}}}_{\overline{d p}}\right)
\end{aligned}
$$

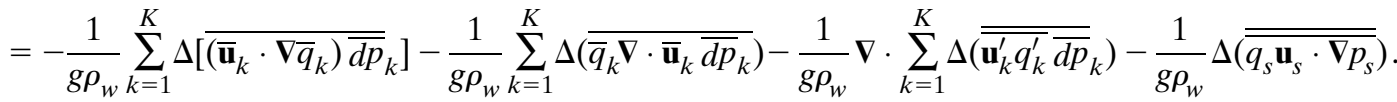




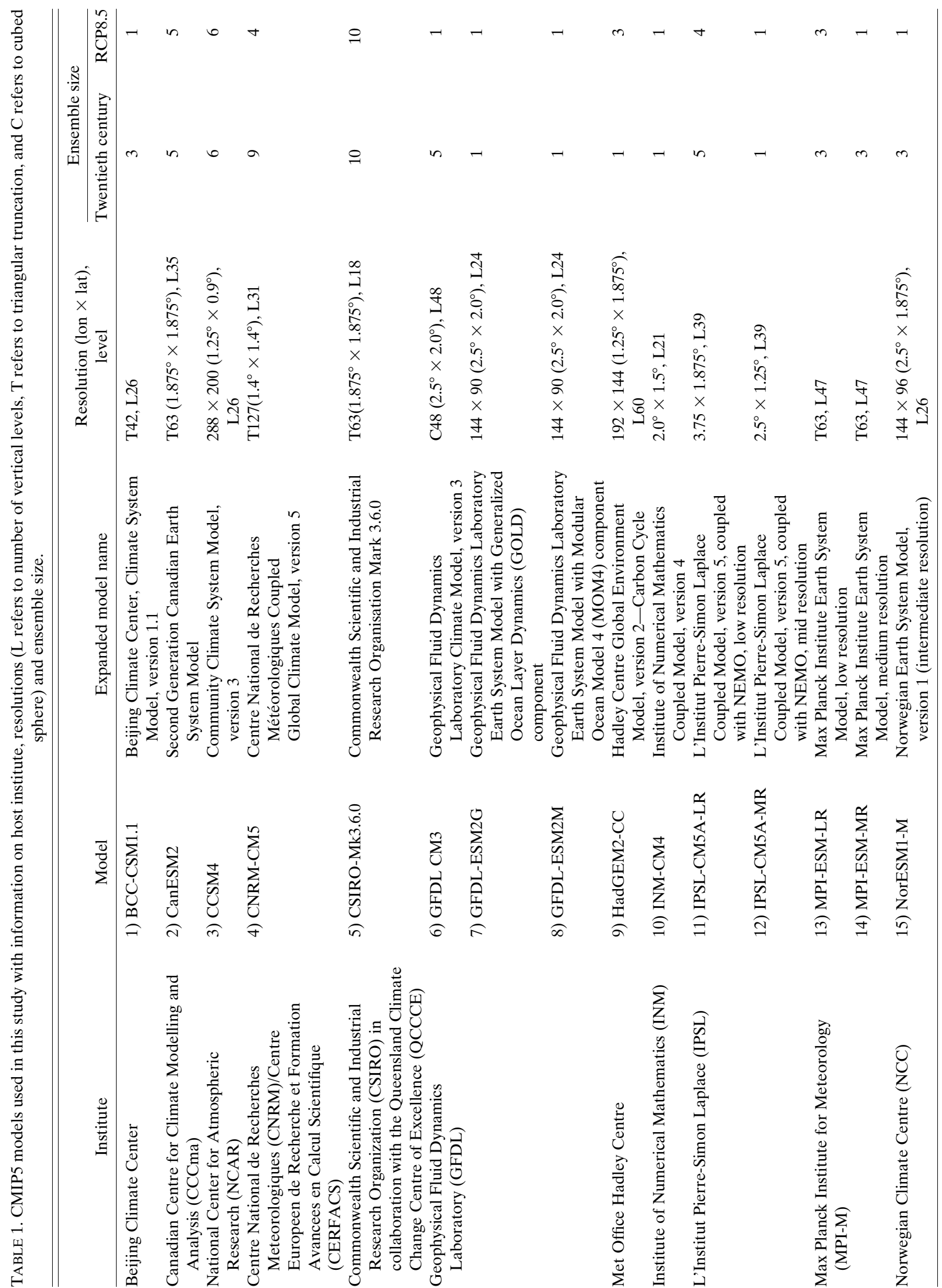


Changes in the first and second terms of Eq. (7) can arise from either changes in humidity or changes in the circulation, with the first being a thermodynamical mechanism and the latter being a dynamical mechanism, for hydrological change (Seager et al. 2010). The thermodynamical and dynamical mechanisms can be diagnostically separated out by evaluating these terms holding: first the circulation and second the humidity fixed at their twentiethcentury climatological values. As will be seen, the term related to the divergent flow [the second term in Eq. (7)] is critical. Introducing the subscript 20 to denote twentiethcentury values, we can approximate this term as

$$
\begin{aligned}
-\frac{1}{g \rho_{w}} \sum_{k=1}^{K} \Delta\left(\overline{\bar{q}_{k} \nabla \cdot \overline{\mathbf{u}}_{k} \overline{d p}_{k}}\right) \approx & -\frac{1}{g \rho_{w}} \sum_{k=1}^{K} \Delta\left(\overline{\bar{q}}_{k} \overline{d p}_{k}\right) \nabla \cdot \overline{\overline{\mathbf{u}}}_{k, 20} \\
& -\frac{1}{g \rho_{w}} \sum_{k=1}^{K} \overline{\bar{q}}_{k, 20} \Delta\left(\overline{\nabla \cdot \overline{\mathbf{u}}_{k} \overline{d p}_{k}}\right),
\end{aligned}
$$

where the approximation comes from ignoring terms quadratic in $\Delta$ and covariances of departures of monthly means from climatological monthly means and from using the twentieth-century values for $d p_{k}$. In Eq. (8), the first term on the right involves the changes in humidity while the circulation is fixed and is the thermodynamic term while the second term involves the changes in the circulation while the humidity is fixed and is the "mean circulation dynamics" term. The monthly mean data were available on 17 levels and the daily data were available on 8 levels so the mean flow moisture convergence was evaluated on 17 levels and the transient eddy moisture convergence was evaluated on just 8 levels, which does introduce some error (SH).

In the appendix, we show the imbalance in the CMIP5 models' climatological moisture budget and argue that this is dominated by underestimation of transient eddy moisture convergence due to use of daily means as opposed to 6 hourly data (as shown in SH). We then show in the appendix that this error is systematic between the twentieth- and twenty-first-century model simulations such that the imbalance in the change in the moisture budget is smaller than both the climatological error and the change in $P-E$ and moisture budget components. Consequently, despite inevitable imbalances in the model moisture budgets, reasonable and informative results can be obtained by their analyses as conducted here.

\section{The climatological Mediterranean moisture budget}

\section{a. Climatological Mediterranean moisture budget in ERA-Interim}

The Mediterranean hydroclimate has a distinct seasonal cycle, and we began by examining the moisture budgets using four seasons. We then determined that brevity is served by presenting the budget in terms of winter (November through April) and summer (May through October) half years without loss of critical information.

The terms in the winter half-year moisture budget within the ERA-Interim are shown in Fig. 1. In this season, all the Mediterranean land areas over Europe and Turkey have an excess of $P$ over $E$ (Fig. 1c). How does the atmosphere converge the moisture needed to balance the positive $P-E$ ? According to ERA-Interim, the winter half-year mean flow converges moisture (Fig. 1d) over Northern Europe but diverges it over most of the Mediterranean, except for a few small areas (e.g., Corsica and the Adriatic Sea). The mean flow moisture divergence arises both from a divergent mean flow over the eastern Mediterranean region, much of North Africa, and the Iberian Peninsula and general dry advection over the region (Fig. 1). In contrast, the transient eddy moisture flux (Fig. 1h) is convergent over all the land areas surrounding the Mediterranean Sea, with the exception of the Nile delta and the coastal area of Libya south of Benghazi, and over Northern European land areas as well. Hence, it is the moisture convergence by the time-varying flow-including storm systems - that provides positive $P-E$ in the Mediterranean land regions during the winter half year. For completeness, the surface term is also shown (Fig. 1g) but does not contribute in a major way to the pattern of Mediterranean region $P-E$.

In the summer half year (Fig. 2), $P$ decreases and $E$ increases over Mediterranean land regions such that, with the exception of the Alps, $P-E$ becomes uniformly negative (Fig. 2c). Indeed in this half year positive $P-E$ is restricted to the northwest British Isles and Scandinavia. The mass divergence term (Fig. 2e) provides mean flow moisture divergence across the Mediterranean region but moistening over northwest Africa. The moisture advection term (Fig. 2f) provides an offsetting wetting over North Africa. The transient eddies contribution (Fig. 2h) is in general weaker but provides some drying over North Africa, northeastern Spain, Italy, Bulgaria, and Romania in this half year.

In sum, the picture arises of storm systems supplying moisture and precipitation to the Mediterranean land regions in winter, with the mean flow moisture divergence opposing, while in summer, when the transient systems no longer converge moisture strongly, the mean flow moisture divergence causes a strong negative $P-E$. The clear exception to this is northwest Africa where, during summer, mean flow moisture convergence is offset by transient divergence. Over the Mediterranean Sea itself $P-E$ is negative throughout the year and, in the winter, 
ERAInt, 1979-2005 Climatology, NDJFMA

a) $\overline{\bar{P}}$

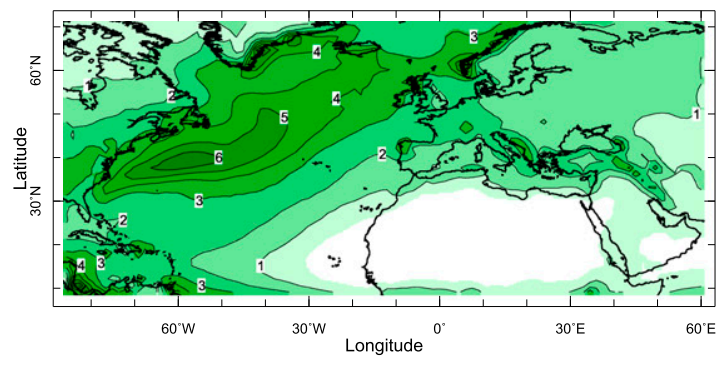

c) $\overline{\bar{P}}-\overline{\bar{E}}$

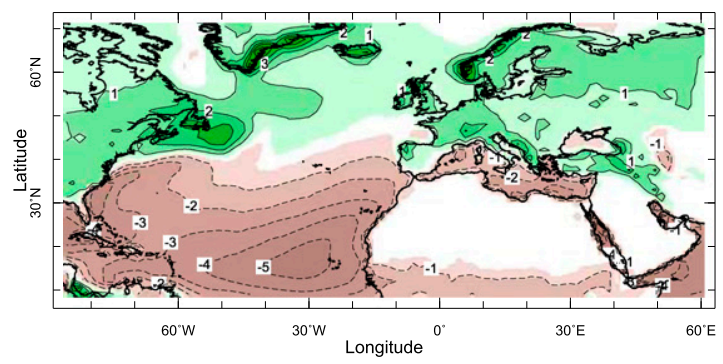

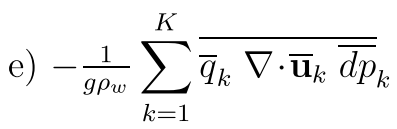

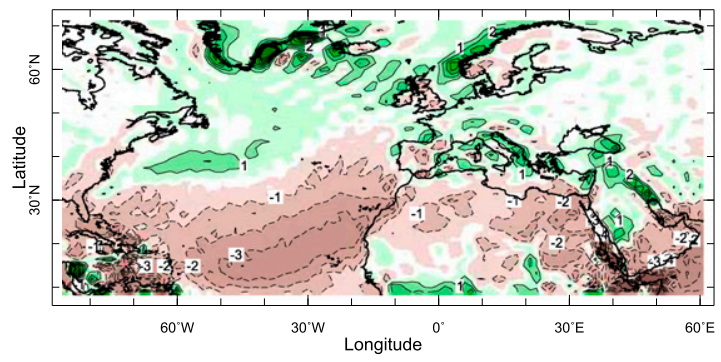

g) $-\frac{1}{g \rho_{w}} \overline{\overline{q_{s} \mathbf{u}_{s} \cdot \nabla p_{s}}}$

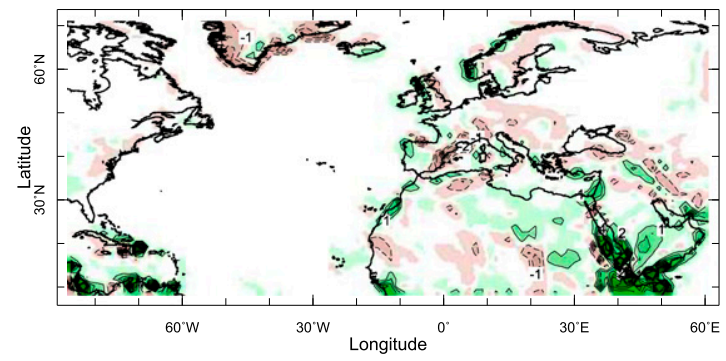

b) $\overline{\bar{E}}$

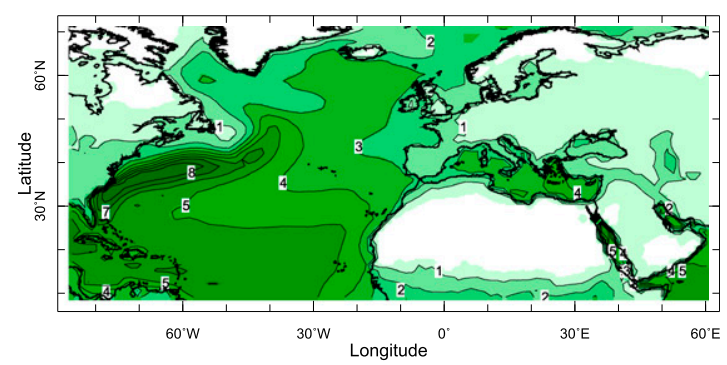

d) $-\frac{1}{g \rho_{w}} \nabla \cdot \sum_{k=1}^{K} \overline{\mathbf{u}}_{k} \bar{q}_{k} \overline{d p}_{k}$

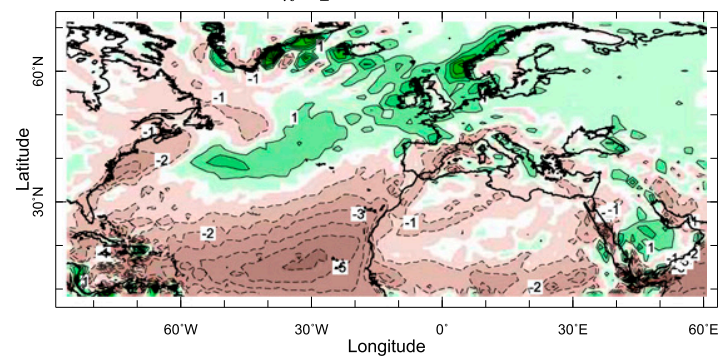

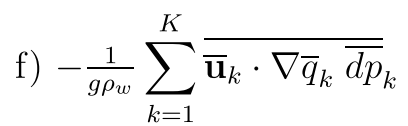

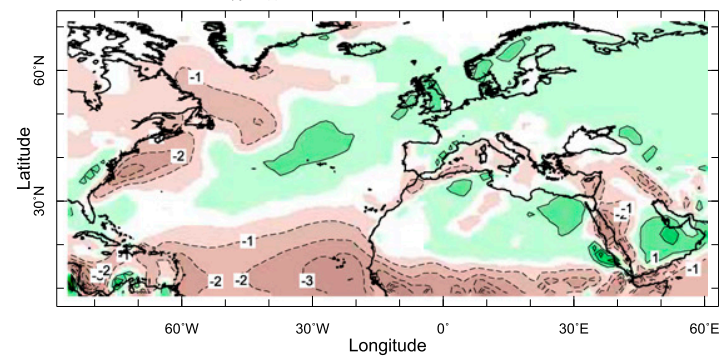

h) $-\frac{1}{g \rho_{w}} \nabla \cdot \sum_{k=1}^{K} \overline{\overline{u_{k}^{\prime} q_{k}^{\prime}}} \overline{d p}_{k}$

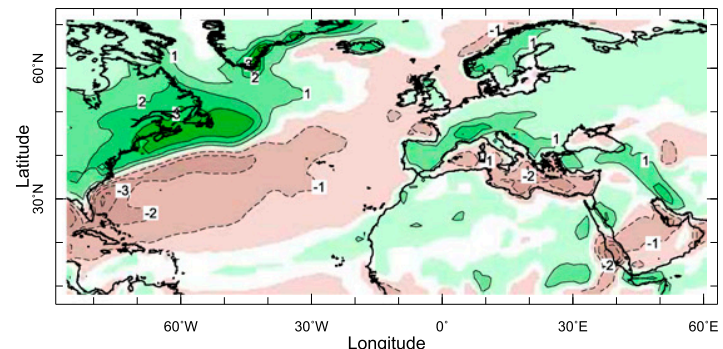

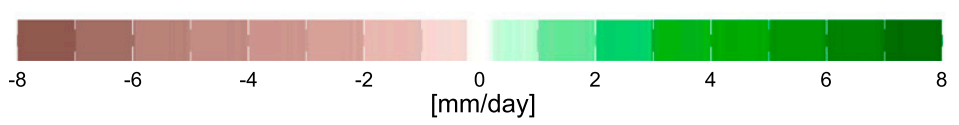

FIG. 1. The November-April half-year climatological moisture budget from ERA-Interim: (a) $P$, (b) $E$, and (c) $P-E$. (d) The moisture convergence by the mean flow and its components due to (e) mass divergence and (f) advection. (h) The transient eddy moisture convergence and $(\mathrm{g})$ the surface term. 
ERAInt, 1979-2005 Climatology, MJJASO

a) $\overline{\bar{P}}$

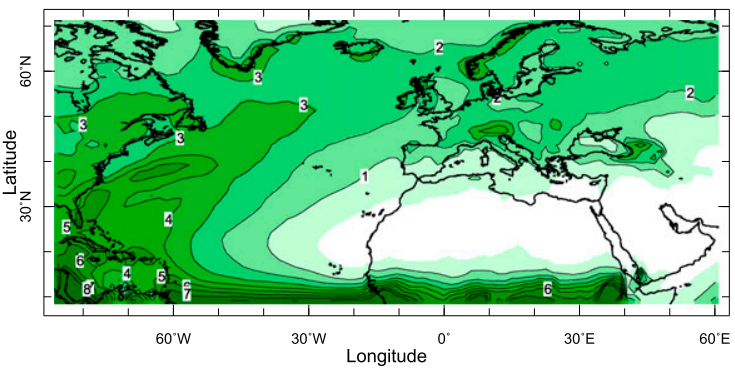

c) $\overline{\bar{P}}-\overline{\bar{E}}$

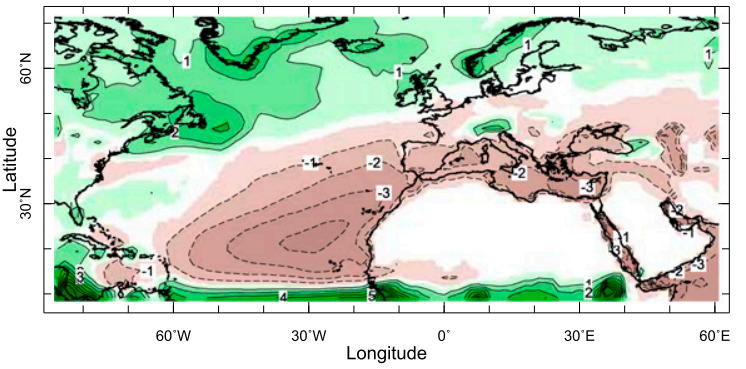

e) $-\frac{1}{g \rho_{w}} \sum_{k=1}^{K} \overline{\bar{q}}_{k} \nabla \cdot \overline{\mathbf{u}}_{k} \overline{\overline{d p}}_{k}$

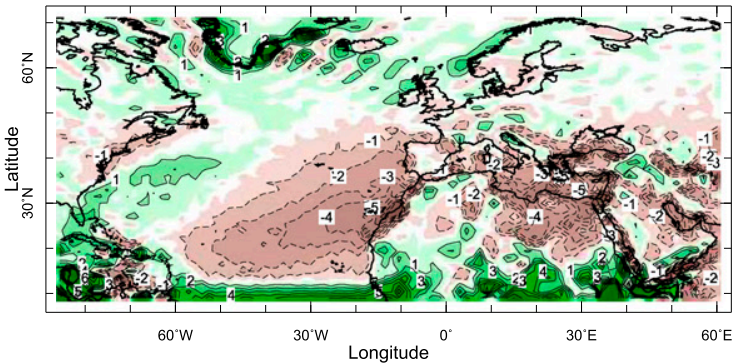

g) $-\frac{1}{g \rho_{w}} \overline{\overline{q_{s} \mathbf{u}_{s} \cdot \nabla p_{s}}}$

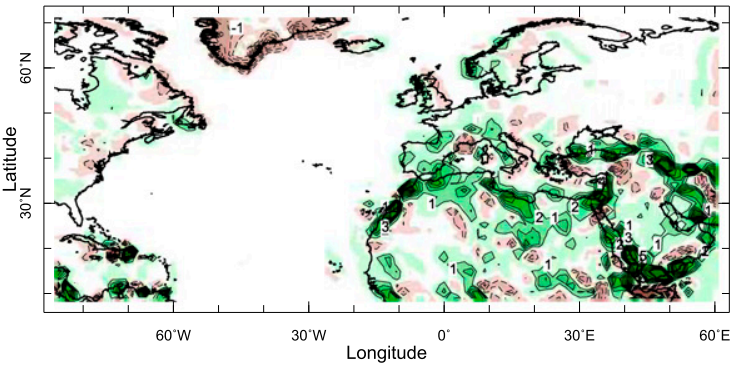

b) $\overline{\bar{E}}$

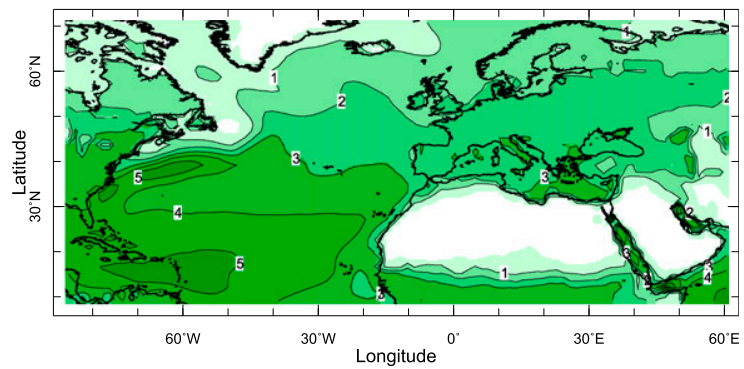

d) $-\frac{1}{g \rho_{w}} \nabla \cdot \sum_{k=1}^{K}{\overline{\mathbf{u}_{k}}}_{\bar{q}_{k} \overline{d p}_{k}}$

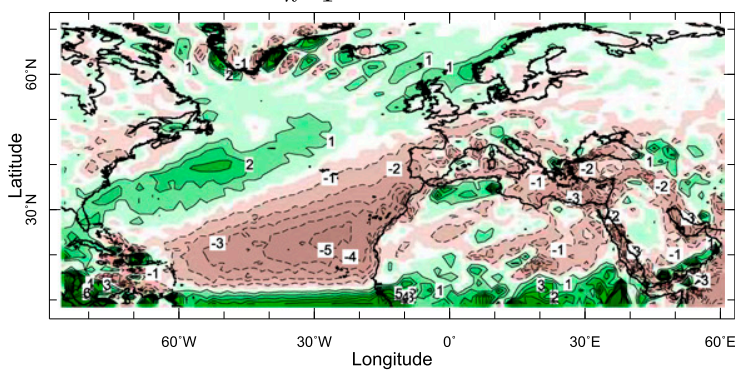

f) $-\frac{1}{g \rho_{w}} \sum_{k=1}^{K} \overline{\mathbf{u}}_{k} \cdot \nabla \bar{q}_{k} \overline{d p}_{k}$

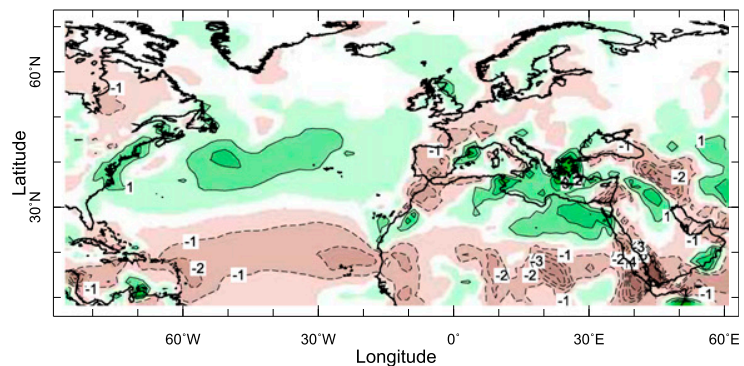

h) $-\frac{1}{g \rho_{w}} \nabla \cdot \sum_{k=1}^{K}{\overline{\overline{u_{k}^{\prime} q_{k}^{\prime}}}}_{\overline{d p}}^{k}$

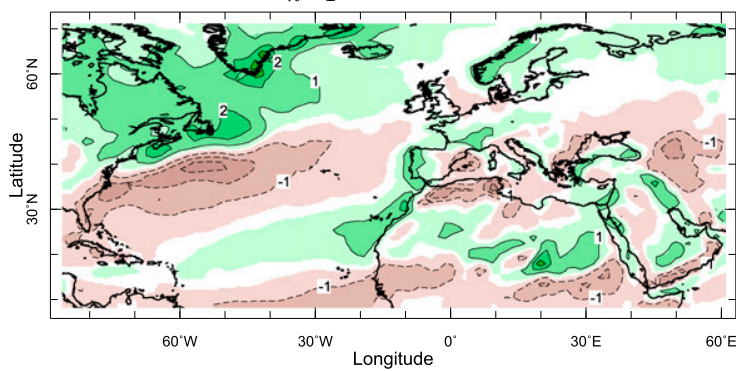

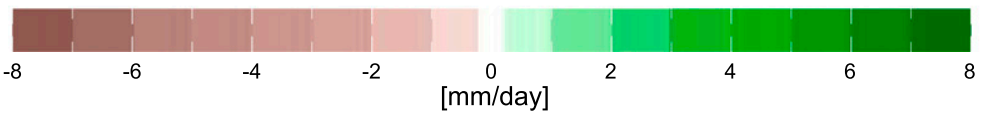

FIG. 2. As in Fig. 1, but for the May-October half year. 
acts as a supplier for $P$ over land while, in the annual mean, the resulting tendency to increasing salinity is balanced via input from river runoff and salt export to the Atlantic through the Straits of Gibraltar (all as deduced in an earlier analysis of reanalyses by Mariotti et al. 2002).

\section{b. Climatological Mediterranean moisture budget in CMIP5 models}

Next we consider how well the moisture budget that sustains the seasonal variations of $P-E$ is represented in the CMIP5 models by focusing on the multimodel mean shown in Figs. 3 and 4 . Winter $P$ (Figs. 3a) is well modeled with modest amounts along the north coast of Africa and much higher amounts on the north shores of the Mediterranean, although the models fail to simulate the heavy $P$ in the Balkans, which is no doubt of orographic origin. The models capture the year-round excess of $E$ over $P$ over the Mediterranean Sea (Fig. 3c). The models also agree with ERA-Interim that the mean flow (Fig. 3d) causes moisture divergence in winter across most of the Mediterranean land and sea regions with the exception of the Adriatic Sea. The models erroneously have mean flow moisture convergence over the Balkans and Turkey. The models also agree with ERA-Interim that the divergent flow (Fig. 3e) is responsible for much of this. However, while ERAInterim has drying by moisture advection across much of Southern Europe and the eastern Mediterranean, the models restrict advective drying to the latter region only (Fig. 3f). However, the models agree with ERA-Interim that it is the transient eddy moisture convergence (Fig. $3 h$ ) that supplies moisture (and positive $P-E$ ) to the land regions north of the Mediterranean Sea while extracting moisture from the sea itself. The transient eddy moisture convergence to the north of the sea is, however, weaker than that observed, which is probably partly due to the use of daily means as opposed to higher temporal resolution data but is perhaps also related to the inability of global climate models to properly represent Mediterranean region storm systems (Ziv et al. 2013).

In the summer half year (Fig. 4) the models correctly show the widespread negative $P-E$ (Fig. 4c) across the Mediterranean region (except for the Alps). The models agree with ERA-Interim that the divergent mean flow (Fig. 4e) is a main cause of drying but is a moistening term over northwest Africa and that it is offset in the central and eastern Mediterranean region by moisture advection (Fig. 4f). The models also agree with ERAInterim that the transient eddies (Fig. $4 \mathrm{~h}$ ) provide some moisture divergence for the central Mediterranean region and northwest Africa in the summer half year.

The comparison of models to ERA-Interim shows a reasonable ability of the current generation of global climate models to simulate the main aspects of the climatological hydrological cycle in the Mediterranean region. The transient eddy moisture flux convergence agreement might also have been better if higher temporal and vertical resolution data had been used for the models as they were for ERA-Interim. While differences remain - probably related to the inability of global climate models of limited spatial resolution to represent the complex topography of the region, as well as to simulate the storm systems within the Mediterranean storm track-the large-scale picture is sufficiently well modeled that it makes sense to consider the change in the moisture budget that occurs in response to human-driven climate change.

\section{Modeled near-term future changes in the Mediterranean region hydroclimate}

Kelley et al. (2011) have shown that the CMIP3 models project that the Mediterranean region will become progressively more arid over the current century as a consequence of human-driven climate change. Given that we have just shown that, in ERA-Interim and CMIP5 models, it is the transient eddies that sustain positive $P-E$, it might be expected that drying would be related to a weakening of the transient eddy moisture convergence. To see if this is the case or if other processes are responsible, we next analyze the change in the moisture budget and its constituent terms between a near-term future, 2021-40, relative to the 1979-2005 period and looking at each half year.

\section{a. Model-projected hydroclimate changes in the winter half year}

The projections for the winter half year are shown in Fig. 5. The term $P$ is projected to decline across North Africa, Portugal, Spain, southern France, Italy, the Balkans, Greece, Turkey, and the Middle East. At the same time, the winter half-year $E$ is projected to increase, except in northwest Africa (where it declines) and the Iberian Peninsula, where the changes are small (probably, in both regions, because of drying soils). Consequently, the changes in the net surface water flux, $P-E$, shows a striking aridification of the hydroclimate (Fig. 5c). While the transient eddy moisture fluxes (Fig. 5h) extract more moisture from the Mediterranean Sea, they actually act to increase moisture convergence (and increase $P-E$ ) on the Iberian Peninsula, southern France, the Alps, and Turkey. There is, however, reduced transient eddy moisture convergence over Italy and the Balkans. The more general and widespread decline in winter half-year $P-E$ is driven by an increase in the mean flow moisture flux divergence (Fig. 5d). This, in turn, is 
CMIP5, 1979-2005 Climatology, NDJFMA

a) $\overline{\bar{P}}$

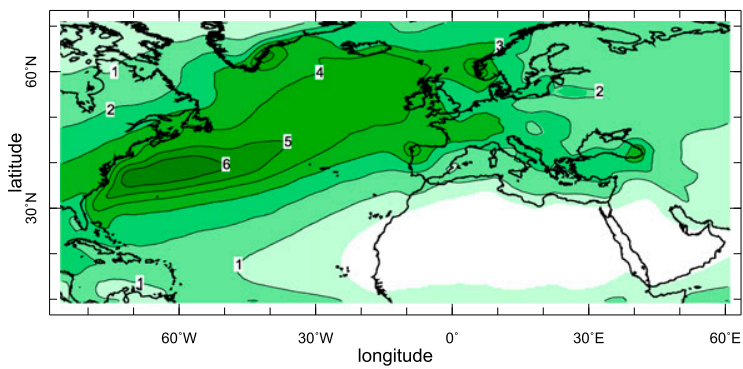

c) $\overline{\bar{P}}-\overline{\bar{E}}$

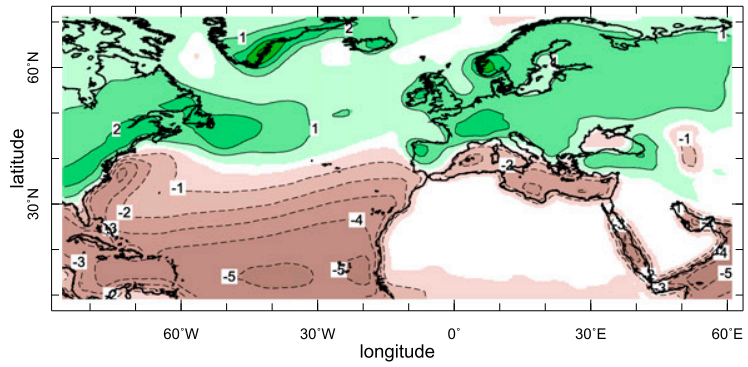

e) $-\frac{1}{g \rho_{w}} \sum_{k=1}^{K}{\overline{q_{k}} \nabla \cdot \overline{\mathbf{u}}_{k} \overline{d p}_{k}}$

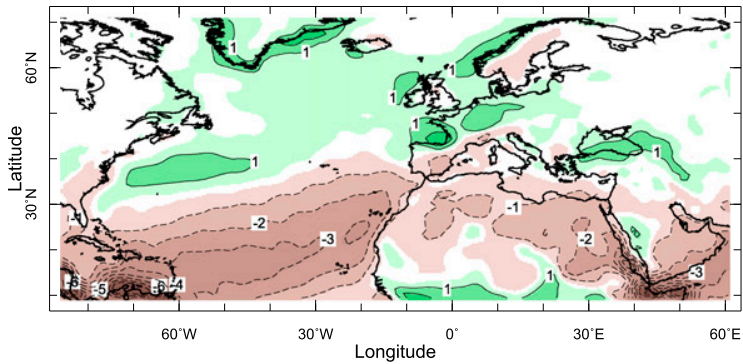

g) $-\frac{1}{g \rho_{w}} \overline{\overline{q_{s} \mathbf{u}_{s} \cdot \nabla p_{s}}}$

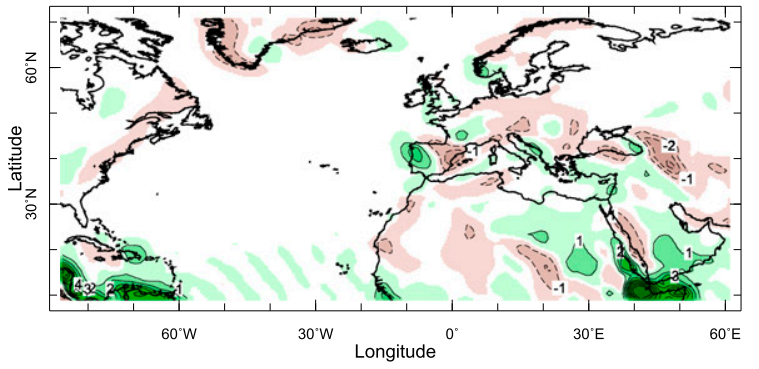

b) $\bar{E}$

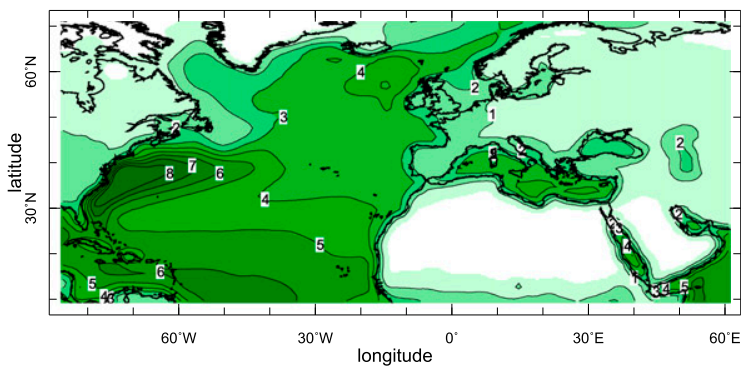

d) $-\frac{1}{g \rho_{w}} \nabla \cdot \sum_{k=1}^{K} \overline{\overline{\mathbf{u}}}_{k} \bar{q}_{k} \overline{d p}_{k}$

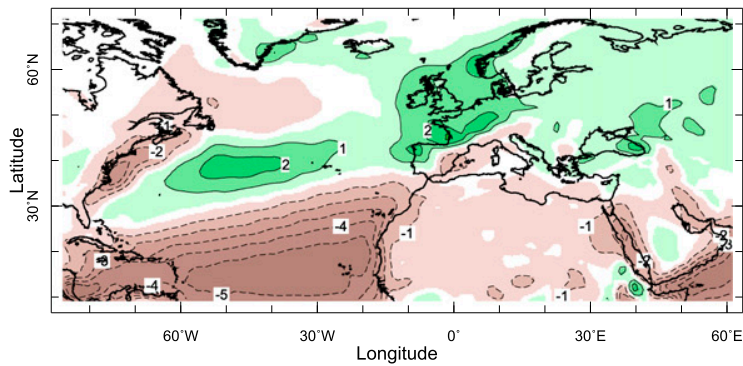

f) $-\frac{1}{g \rho_{w}} \sum_{k=1}^{K} \overline{\mathbf{u}}_{k} \cdot \nabla \bar{q}_{k} \overline{d p}_{k}$

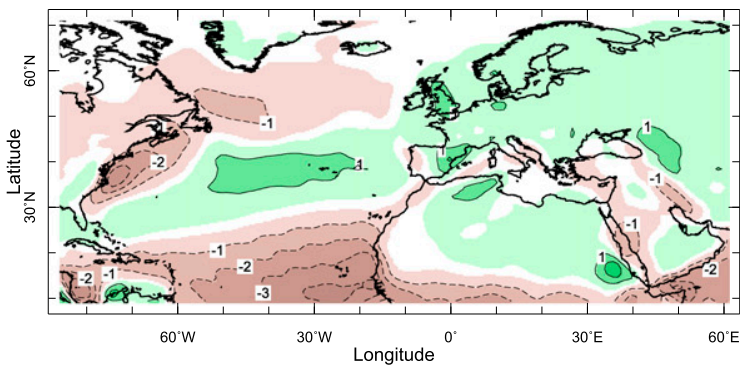

h) $-\frac{1}{g \rho_{w}} \nabla \cdot \sum_{k=1}^{K}{\overline{\overline{u_{k}^{\prime} q_{k}^{\prime}}}}_{\overline{d p}}$

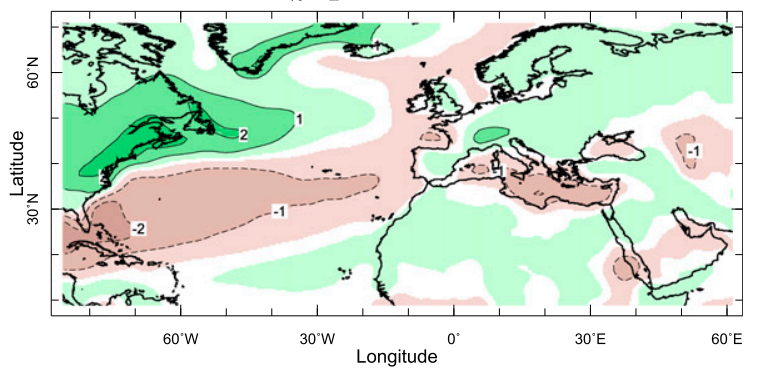

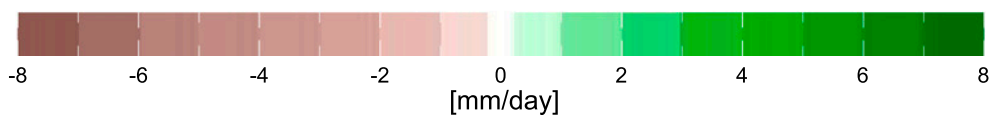

FIG. 3. As in Fig. 1, but showing the moisture budget terms for the multimodel mean of the CMIP5 models for the winter half year. 
CMIP5, 1979-2005 Climatology, MJJASO

a) $\overline{\bar{P}}$

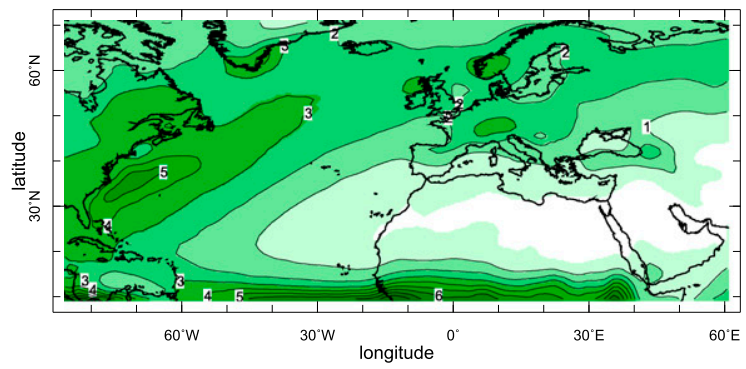

c) $\overline{\bar{P}}-\overline{\bar{E}}$

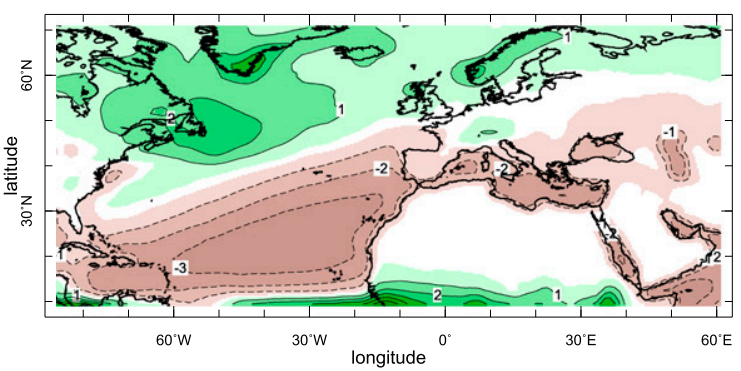

e) $-\frac{1}{g \rho_{w}} \sum_{k=1}^{K} \bar{q}_{k} \nabla \cdot \overline{\mathbf{u}}_{k} \overline{d p}_{k}$

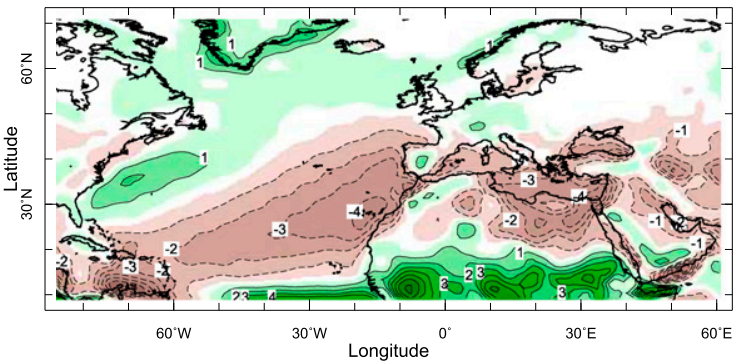

g) $-\frac{1}{g \rho_{w}} \overline{\overline{q_{s} \mathbf{u}_{s} \cdot \nabla p_{s}}}$

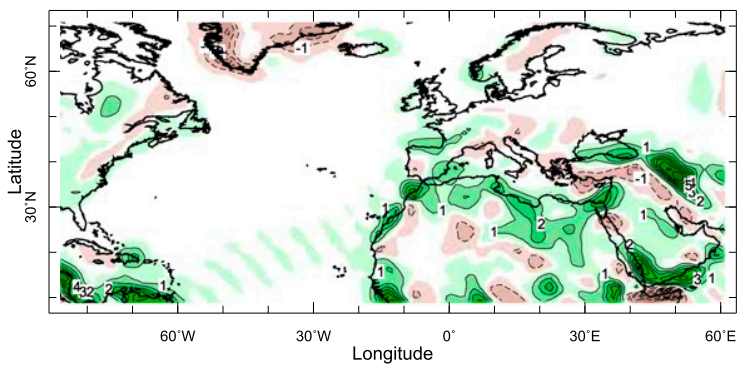

b) $\overline{\bar{E}}$

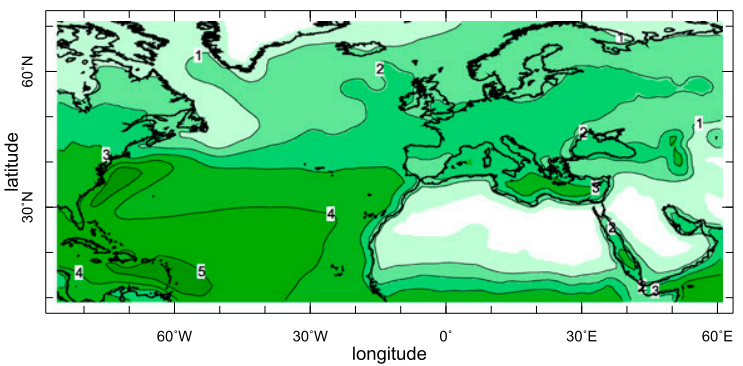

d) $-\frac{1}{g \rho_{w}} \nabla \cdot \sum_{k=1}^{K} \overline{\mathbf{u}}_{k} \bar{q}_{k} \overline{d p}_{k}$

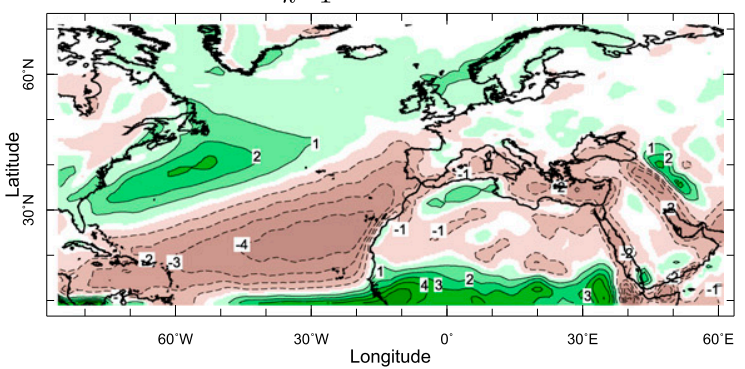

f) $-\frac{1}{g \rho_{w}} \sum_{k=1}^{K}{\overline{\mathbf{u}_{k} \cdot \nabla \bar{q}_{k}} \overline{d p}}_{k}$

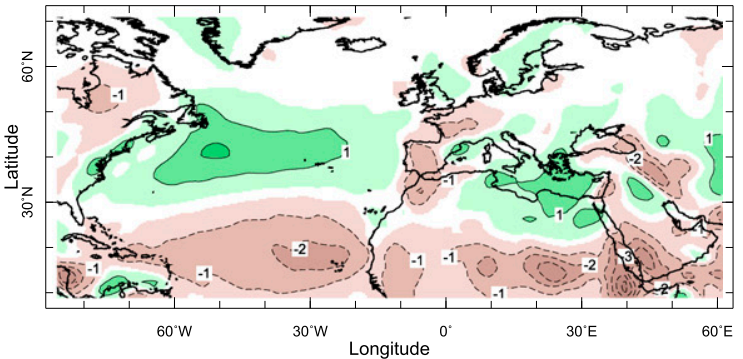

h) $-\frac{1}{g \rho_{w}} \nabla \cdot \sum_{k=1}^{K}{\overline{\overline{u_{k}^{\prime} q_{k}^{\prime}}} \overline{\overline{d p}}}_{k}$

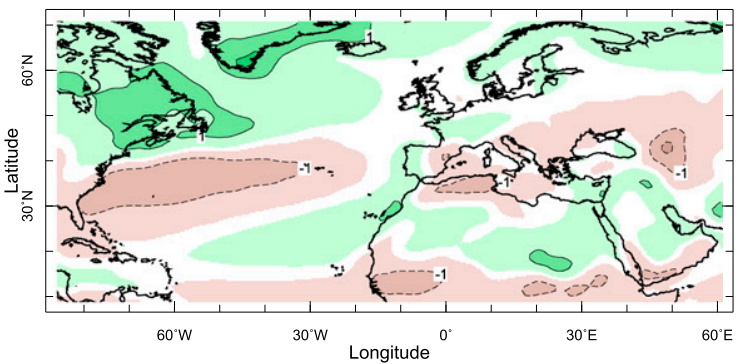

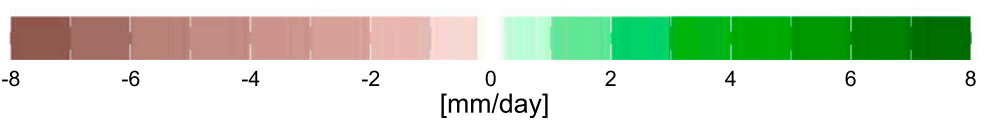

FIG. 4. As in Fig. 2, but showing the moisture budget terms for the multimodel mean of the CMIP5 models for the summer half year. 
a) $\Delta \overline{\bar{P}}$

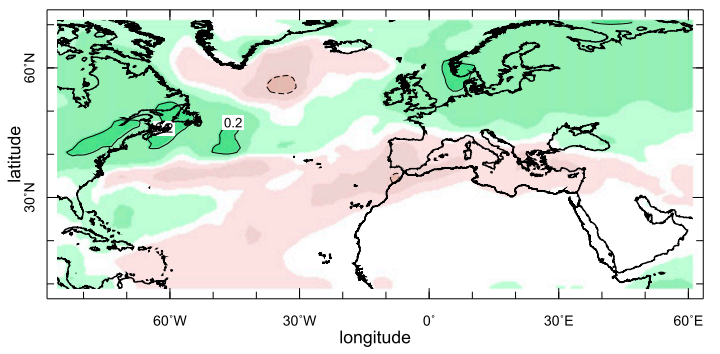

c) $\Delta(\overline{\bar{P}}-\overline{\bar{E}})$

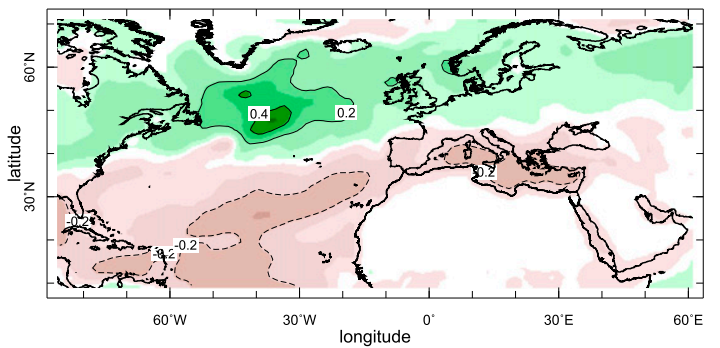

e) $-\frac{1}{g \rho_{w}} \sum_{k=1}^{K} \Delta\left(\overline{\bar{q}}_{k} \nabla \cdot \overline{\mathbf{u}}_{k} \overline{d p}_{k}\right)$

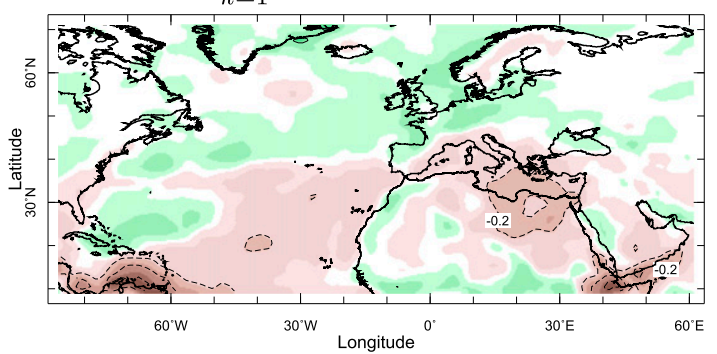

g) $-\frac{1}{g \rho_{w}} \Delta\left(\overline{\overline{q_{s} \mathbf{u}_{s} \cdot \nabla p_{s}}}\right)$
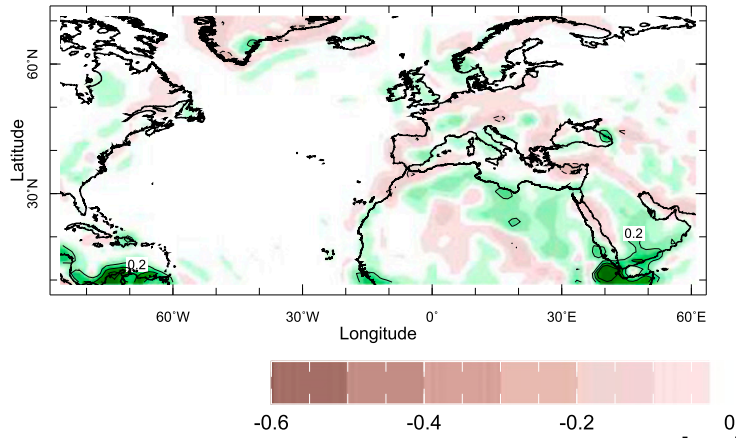

$[\mathrm{mm} / \mathrm{day}]$

FIG. 5. The change from the 1979-2005 period to the 2021-40 period of the component of the moisture budget for the CMIP5 multimodel mean and for the winter half year. The changes in (a) $P$, (b) $E$, and (c) $P-E$. (d) The change in moisture convergence by the mean flow and its component changes due to (e) mass divergence and (f) advection. (h) The change in transient eddy moisture convergence and (g) the change in the surface term. Units are millimeters per day.
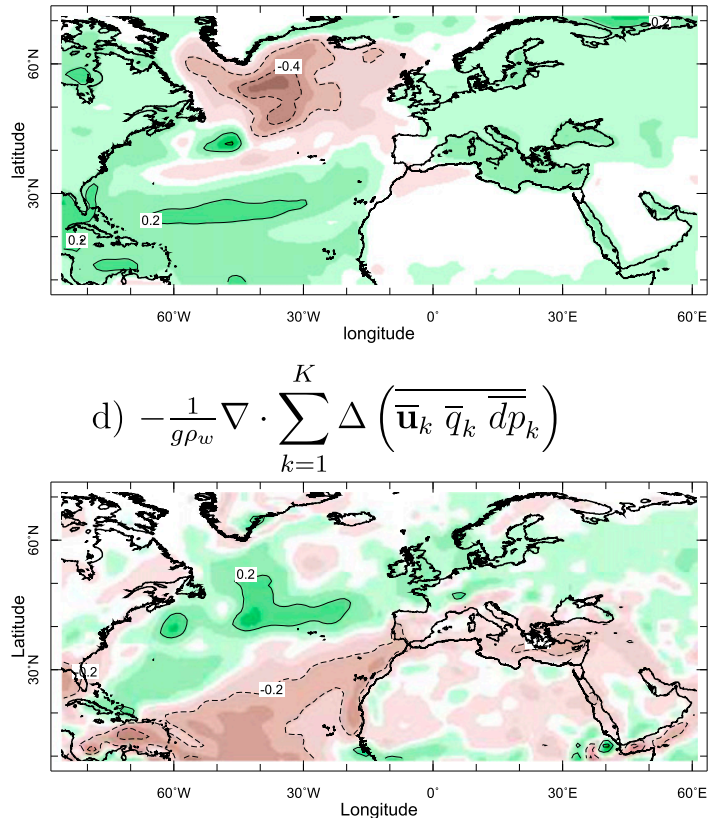

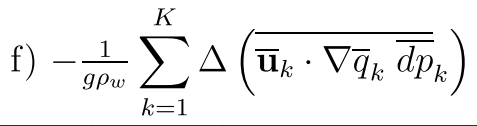

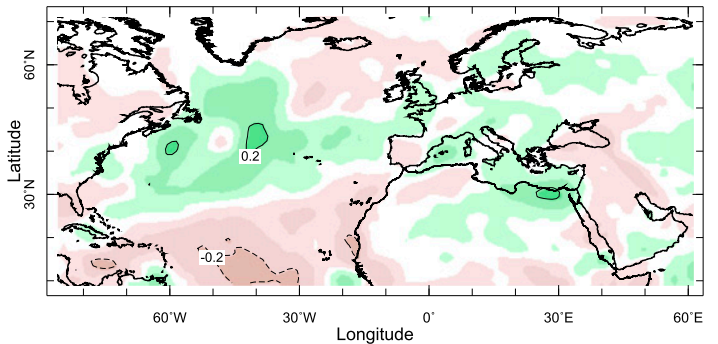

h) $-\frac{1}{g \rho_{w}} \nabla \cdot \sum_{k=1}^{K} \Delta\left({\overline{\overline{u_{k}^{\prime} q_{k}^{\prime}}} \overline{\overline{d p}}}_{k}\right)$
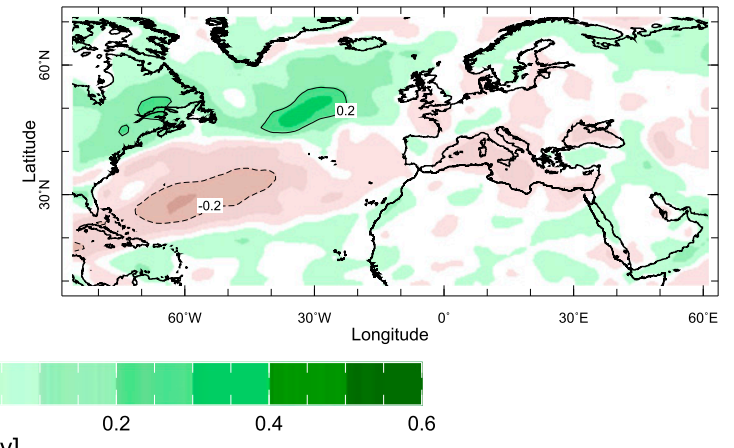
sustained by an increase in the component related to the mass flux divergence (Fig. 5e) while the change in moisture advection (Fig. 5f) also dries the west and east Mediterranean regions but provides for an offsetting moistening in the central region.

\section{b. Model-projected hydroclimate changes in the summer half year}

In the summer half year (Fig. 6) $P$ also drops across the Mediterranean region as well as across all of Europe, except for northeast Scotland, Scandinavia, and the Baltic states. The $E$ also increases except in northwest Africa and the Iberian Peninsula; hence, $P-E$ shows widespread aridification (Fig. 6c). Transient moisture fluxes (Fig. 6h) tend to dry northeastern Spain and southwestern France; the region at the northern end of the Adriatic Sea; and parts of Greece, Turkey, and northwest Africa. As for the winter half year, widespread increasingly negative summer $P-E$ is also balanced by increased mean flow moisture divergence (Fig. 6d). This is particularly so over the Mediterranean Sea while the localized regions of transient eddy drying around the shores tend to be areas of mean flow moistening. The mass divergence component is a strong contributor to a widespread drying tendency. Changes in moisture advection are weaker but moisten the central Mediterranean and dry the eastern and western regions, much as in the winter half year.

\section{c. Robustness of projected changes in $P$ and $P-E$}

To determine how robust the model-projected changes are in the basic quantities of $P$ and $P-E$, we computed the number of models that have a positive change when the multimodel mean change is positive and vice versa for dry changes, with the change evaluated for 2021-40 relative to 1979-2005. Figure 7 shows that across the Mediterranean region more than three-quarters of the models agree that both $P$ and $P-E$ will decline reflecting a high level of model agreement and the robustness of this projected change. Indeed in some subregions of the Mediterranean region all of the models agree on a drying signal, which is truly quite remarkable. Data from more CMIP5 models have become available since this work was begun but, given the level of agreement shown here, it is considered that results will not be appreciably different for a larger model ensemble. Indeed, while we have not performed the moisture budget calculation for more than the 15 models used here, the multimodel mean patterns of $P-E$ and its change for a 35 -model ensemble are very similar to those shown here (see http://kage.ldeo.columbia.edu:81/ SOURCES/.LDEO/.ClimateGroup/.PROJECTS/.IPCC/ .CMIP5/.MultiModelStatistics/).

\section{d. Contribution of humidity change and mean circulation change to the increase in mean flow moisture divergence driving aridification}

In both half years the increasing mean flow moisture divergence is a prime cause of the aridification of the Mediterranean region in the current century. As shown in Eqs. (7) and (8), this can be caused by changes in specific humidity or the mean circulation. These two contributions were separated out and the results are shown in Fig. 8. The simplest component to understand is the thermodynamic one related to an increase in specific humidity as increasing GHG concentration causes the atmosphere to warm. Even in the absence of a change in circulation this causes an increase in moisture convergence where the mean flow is convergent and a decrease where the mean flow is divergent and hence an amplified pattern of $P-E$ referred to as "rich get richer, poor get poorer" or "wet get wetter, dry get drier" (Held and Soden 2006; Chou et al. 2009; Seager et al. 2010). As seen in Fig. 8 (right), this process causes a widespread negative $P-E$ tendency across the subtropical Atlantic Ocean, North Africa, the Mediterranean Sea, southern Europe, and the Middle East and is strongest in the summer half year. The mean circulation dynamics term arises solely from changes in the mean circulation. In the winter half years, this dries a zonal band extending from the southeast United States across the North Atlantic Ocean and encompassing the entire Mediterranean region except for the far western sector. In the summer half year, the change in the mean circulation dynamics creates a drying tendency in the central Mediterranean but a moistening tendency in the western and eastern regions (the Iberian Peninsula, northwest Africa, Turkey, and the Middle East).

\section{e. Summary}

Consultation of the color scales for the climatological and climate change figures shows that the change in $P-E$ can easily exceed $10 \%$ of the mean and reach up to $25 \%$. This reveals an aridification that is yearround; widespread; and, considering the amplitude, quite alarming. Remember that these changes are for the next 2-decade period. As the century advances, the drying gets worse (Mariotti et al. 2009; Kelley et al. 2011). While transient eddies provide for positive $P-E$ over Mediterranean land areas in the current winter climate, they will continue to do so, increasing their contributions, in the coming decades in Spain, France, Turkey, and the Middle East but with reduced convergence over Italy and the Balkans. In contrast, human-driven climate change provides a widespread increase in mean flow moisture divergence that offsets any transient convergence and 
CMIP5, (2021-2040) - (1979-2005), MJJASO

a) $\Delta \overline{\bar{P}}$

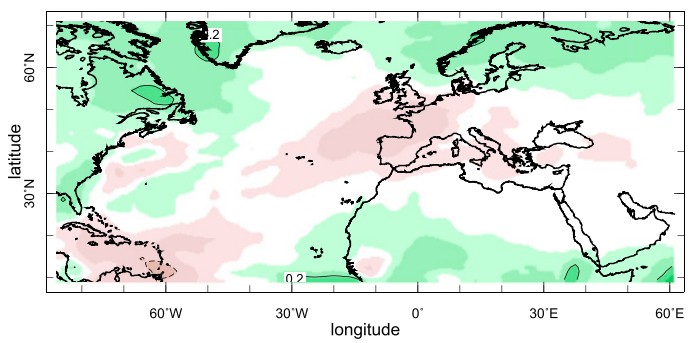

c) $\Delta(\overline{\bar{P}}-\overline{\bar{E}})$

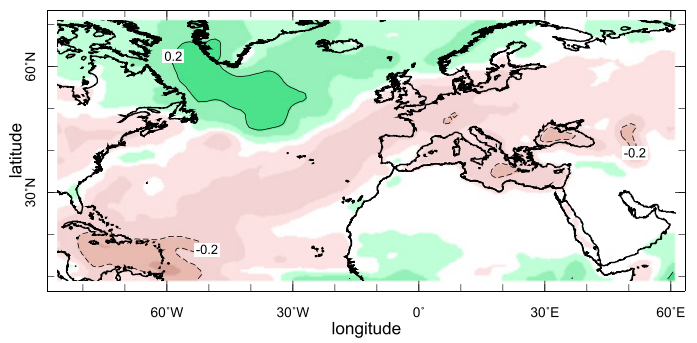

e) $-\frac{1}{g \rho_{w}} \sum_{k=1}^{K} \Delta\left(\overline{\bar{q}}_{k} \nabla \cdot \overline{\mathbf{u}}_{k} \overline{\overline{d p}}_{k}\right)$

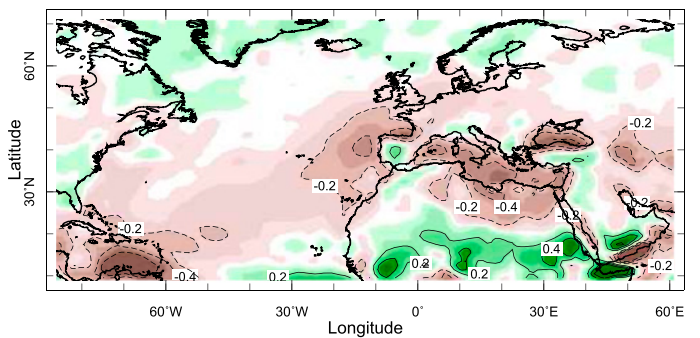

g) $-\frac{1}{g \rho_{w}} \Delta\left(\overline{\overline{q_{s} \mathbf{u}_{s} \cdot \nabla p_{s}}}\right)$

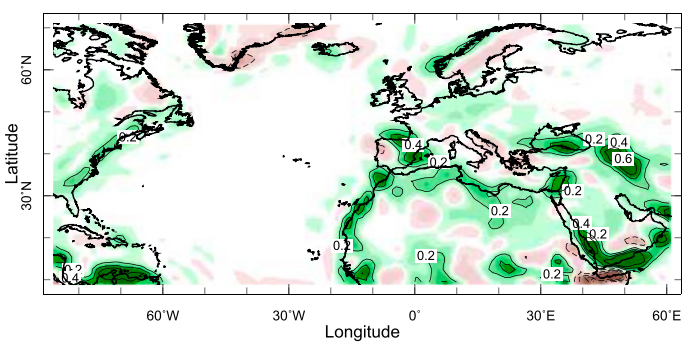

b) $\Delta \overline{\bar{E}}$

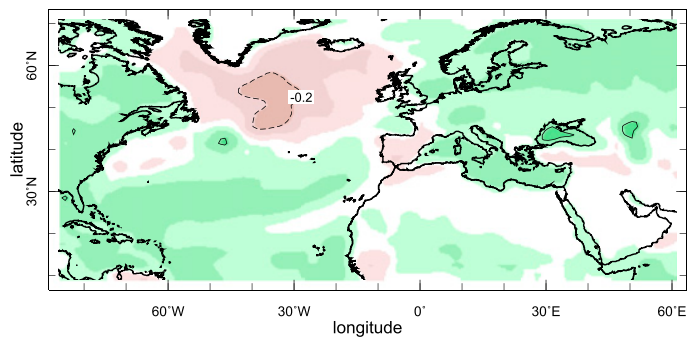

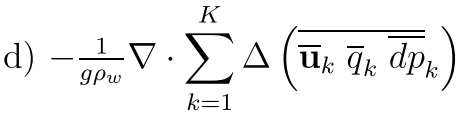

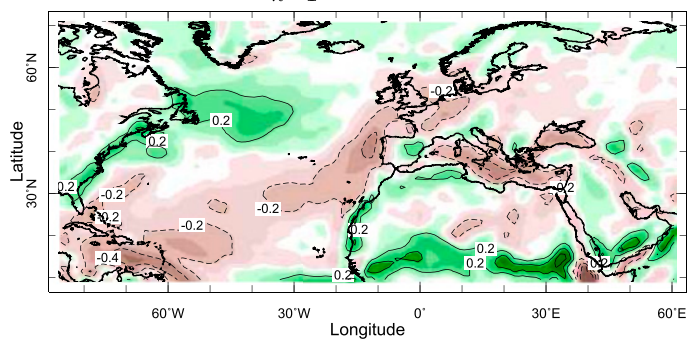

f) $-\frac{1}{g \rho_{w}} \sum_{k=1}^{K} \Delta\left(\overline{\overline{\mathbf{u}}}_{k} \cdot \nabla \bar{q}_{k} \overline{d p}_{k}\right)$

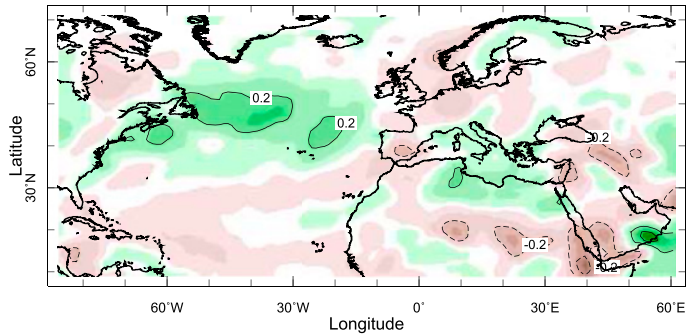

h) $-\frac{1}{g \rho_{w}} \nabla \cdot \sum_{k=1}^{K} \Delta\left(\overline{\overline{u_{k}^{\prime} q_{k}^{\prime}}} \overline{\overline{d p}}\right)$

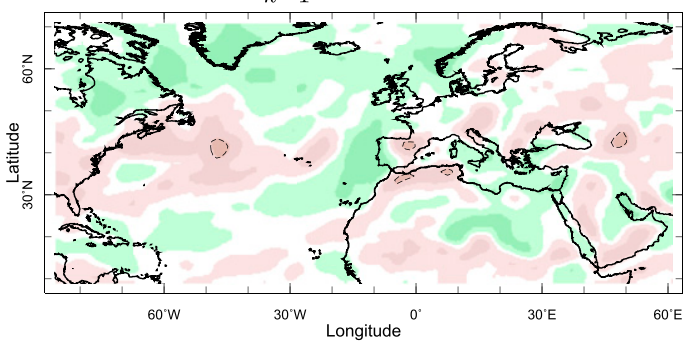

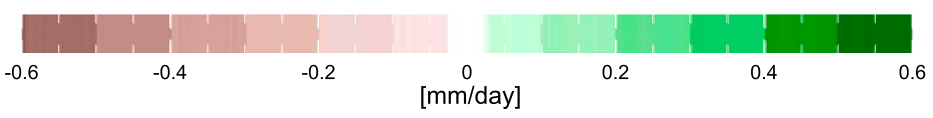

FIG. 6. As in Fig. 5, but for the summer half year. Units are millimeters per day. 
CMIP5, number of models matching mean (color and contour), (2021-2040) - (1979-2005)

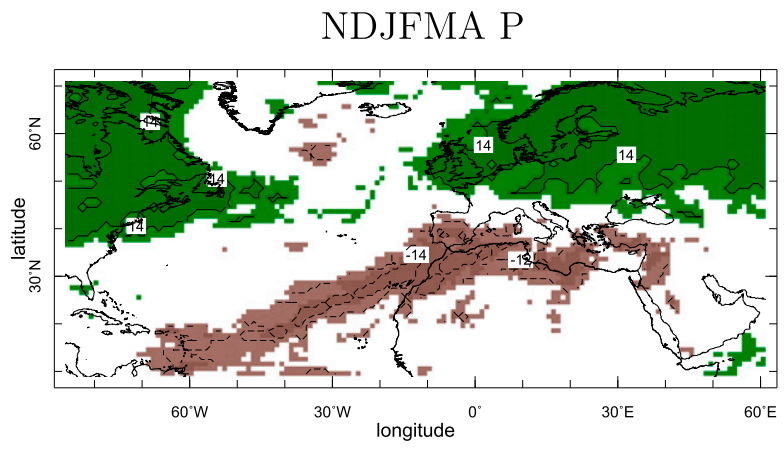

NDJFMA P - E

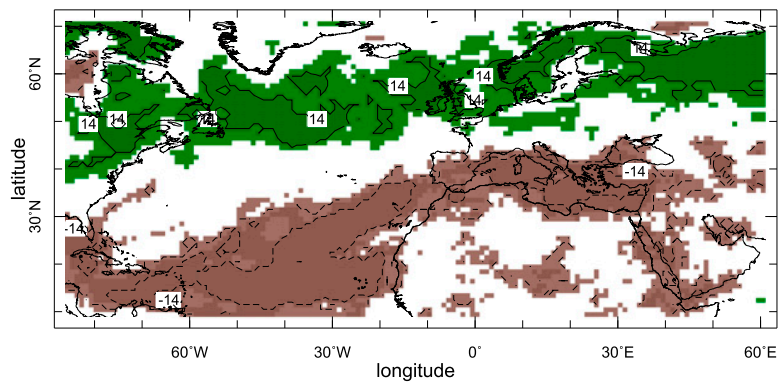

MJJASO P

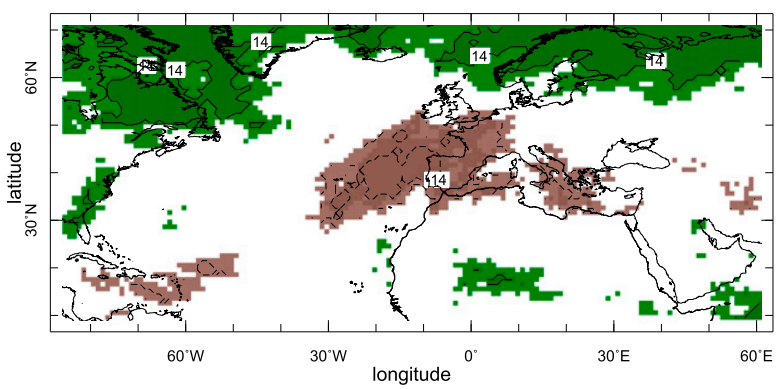

MJJASO P - E

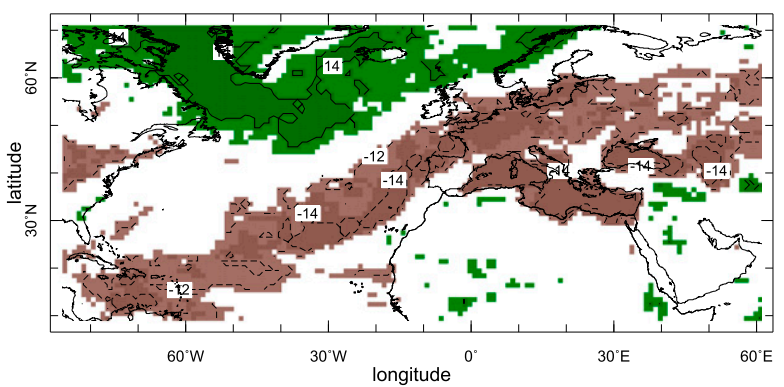

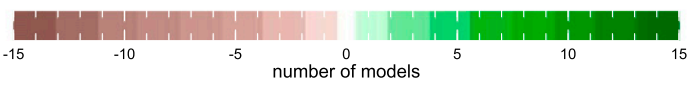

FIG. 7. The number of models that agree with the multimodel mean change in (top) precipitation and (below) precipitation minus evaporation for (left) and summer (right) winter half years; 15 models were used and values are only plotted when 12 or more (roughly three-quarters) of the models agree on the sign of the change.

results in a pan-Mediterranean year-round decrease in $P-E$. Hence, the mean flow moisture divergence is an important driver of increased aridification of the Mediterranean region in the coming decades and in both half years.

\section{Relating the projected changes in Mediterranean hydroclimate to changes in the mean and transient atmospheric circulation}

We have identified that aridification of the Mediterranean region in coming decades is related to increases in the moisture divergence by the mean flow and, in particular, to the part of that related to a change in the mass divergent flow itself. Here we analyze the changes in the atmospheric circulation that cause this. Figure 9 shows that the multimodel mean change in both the winter and summer half years is toward low-level $(925 \mathrm{mb})$ divergence. The summer half-year change is rather widespread. In contrast, the winter half-year changes appear as a narrow zonal strip extending from the southeast
United States across the Atlantic Ocean and then across the Mediterranean region. This definitely has the appearance of an expansion of the winter Hadley cell (see Seager et al. 2010) but with some modification that results in the largest subsidence concentrated on the eastern side of the Mediterranean.

Next, Fig. 10 shows the changes in geopotential heights at $850 \mathrm{mb}$ and the upper $(250 \mathrm{mb})$ and lower $(700 \mathrm{mb})$ transient eddy activity, as measured by the submonthly variance of meridional velocity, as well as the climatological values for the 1979-2005 period. At the upper levels during winter, there is a clear North Atlantic storm track that extends southwest-northeast into northwest Europe but there is no well-defined Mediterranean storm track consistent with other estimates of storm-track activity based on upper-tropospheric bandpassed variances (e.g., Chang et al. 2002). Uppertropospheric meridional velocity variance increases almost everywhere in the North America-Atlantic-Europe sector for the winters of the 2021-40 period, with declines limited to some subtropical areas. In contrast to the 
CMIP5, (2021-2040) - (1979-2005)

NDJFMA
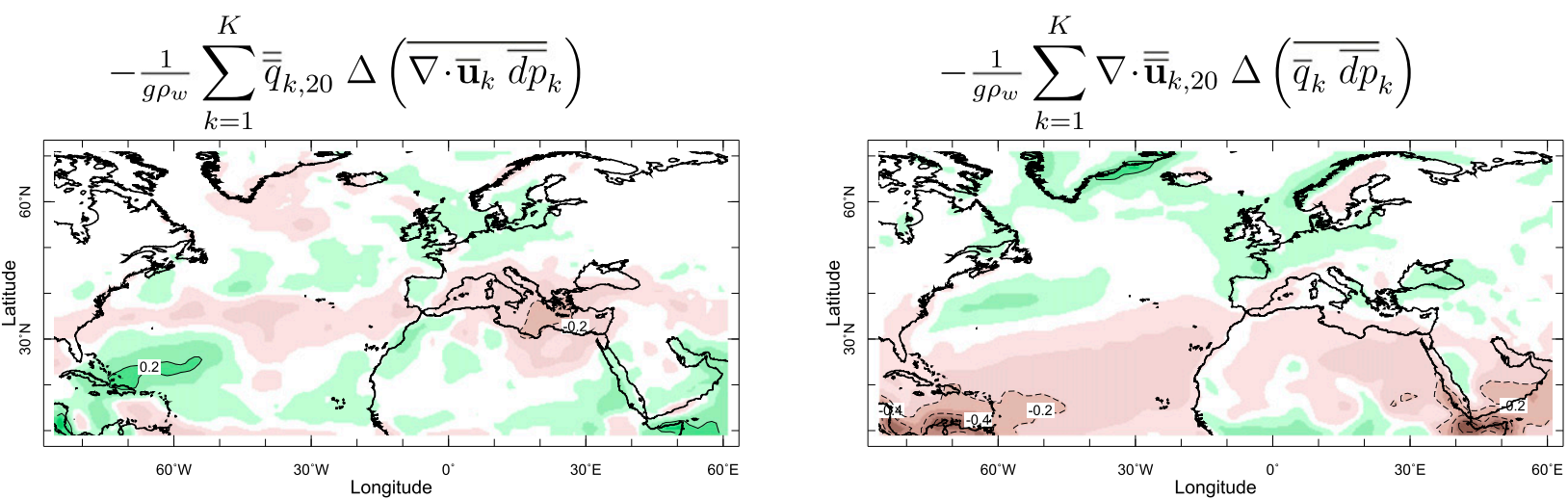

MJJASO

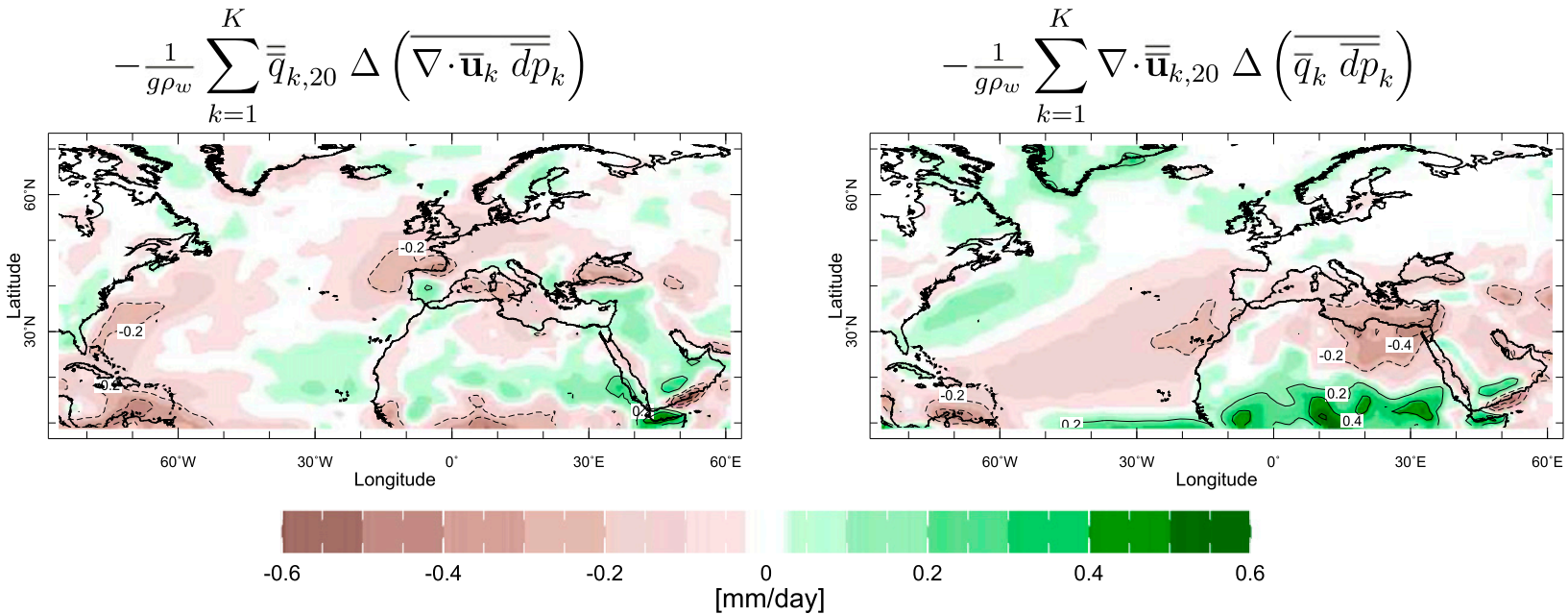

FIG. 8. The mean circulation (left) dynamical and (right) thermodynamical contributions to the change in the mean flow moisture convergence for the CMIP5 multimodel mean for the (top) winter half year and (bottom) summer half year. Units are millimeters per day.

upper troposphere, at the 700-mb level the meridional velocity variance shows a distinct Mediterranean storm track separate from the Atlantic storm track. At this lower level, the variance declines for the 2021-40 winter period almost everywhere, except for a few isolated regions (e.g., west of Ireland). These changes are consistent with those shown by Chang et al. (2012) and are part of a strengthening and upward and poleward shift of the storm track in the Northern Hemisphere upper troposphere with weakening at lower levels. These changes are themselves likely related to the reduced low-level meridional temperature gradient (a consequence of Arctic amplification of global warming; Chang et al. 2012) and the increase in temperature gradient at the tropopause level (a consequence of stratospheric cooling and enhanced warming in the tropical upper troposphere).
In the summer half year (Fig. 10, middle) there is a clear poleward shift of the storm track at upper levels, which results in a weakening over the Mediterranean region. At lower levels, the summer storm track weakens, especially on its equatorward flank, including over the Mediterranean region. For both summer and winter, the storm-track weakening at lower levels is, however, quite weak.

It might be thought that the lower-troposphere eddy variance is of most relevance for precipitation since moisture is concentrated in the lower levels of the atmosphere. If so, then the fact that the transient eddies are, if anything, converging more moisture onto eastern and western land regions north of the Mediterranean Sea in the future than in the past is not because the eddies themselves strengthen. Instead it probably arises from 
CMIP5, (2021-2040) - (1979-2005), $\Delta(-\nabla \cdot \overline{\overline{\mathbf{u}}})$ at $925 \mathrm{mb}$
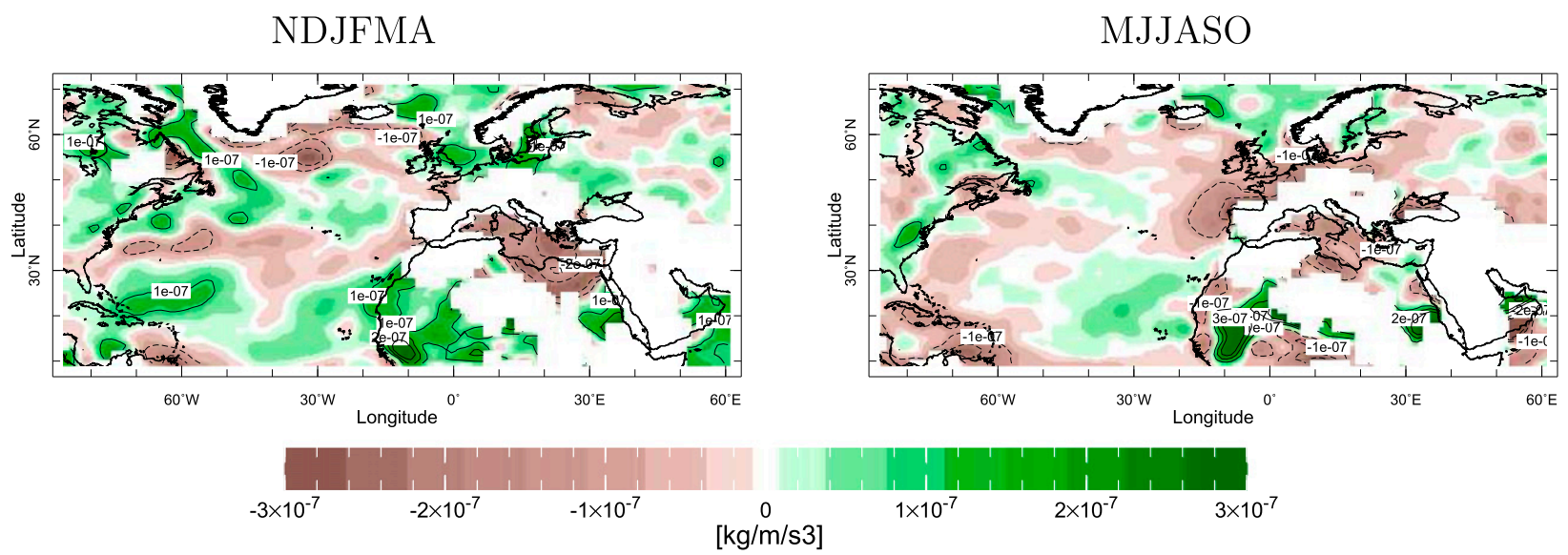

FIG. 9. The multimodel mean change from 1979-2005 to 2021-40 in the low-level (925 mb) mean convergence for the (left) winter and (right) summer half years. Negative changes imply increased low-level divergence. Units are $\mathrm{s}^{-1}$.

larger gradients of moisture that allow for increased moisture transport and convergence by the eddy field even as the latter weakens. To show that this might be the case, Fig. 11 plots the change in surface to $600-\mathrm{mb}$ vertically integrated moisture content for the two half years. In general, regions of increased transient eddy moisture flux convergence, such as the Alps and Turkey during the winter half year, lie on the poleward flank of regions where there is an increase in the moisture gradient because of larger increases in moisture over the Mediterranean Sea than over Europe. In the case of meridional gradients, the humidity anomalies within a storm $q^{\prime}$ are often approximated by $-L \partial \bar{q} / \partial y$, where $L$ is an eddy length scale. Hence, $v^{\prime} q^{\prime}$ and transient eddy moisture convergence can increase even if the eddies themselves $\left(v^{\prime}\right)$ weaken.

The changes in the 850-mb geopotential height show (apart from an overall increase due to atmospheric warming) a very strong localized low-level high centered over Italy in the winter half year, an authentically bull'seye feature (Fig. 10, bottom). There is a relative low height anomaly centered north of the British Isles, so this is to some extent a north-south dipole, but the anomalous Mediterranean high is the much stronger feature. In the summer half year, there is a high geopotential anomaly extending from the northeast United States across the North Atlantic Ocean, where it reaches maximum strength southwest of the British Isles, and then extending but weakening into Northern Europe. In both half years, these patterns are very similar to those identified in sea level pressure by Giorgi and Coppola (2007) using the CMIP3 model archive. It is expected, according to vorticity and thermal balances, that subsidence and low-level divergence will occur on the eastern flanks of low-level highs where the flow is northerly and, comparing Figs. 9 and 10, this appears to be the case with low-level divergence a maximum over the eastern Mediterranean region in winter and over the entire Mediterranean in summer. These changes in the heights and divergence are then consistent with the changes in $P-E$ induced by mean divergence flow anomalies shown in Fig. 8.

\section{Conclusions and discussion}

\section{a. Conclusions}

The atmospheric branch of the hydrological cycle over the Mediterranean region, as well as its model-projected change for the coming decades, has been investigated and the following conclusions have been reached:

- According to ERA-Interim, positive $P-E$ over the Mediterranean region land areas in the winter half year is sustained by transient eddy moisture flux convergence and opposed by moisture divergence by the mean flow. In the summer half year the transient eddy moisture flux convergence is weak but mean flow moisture divergence continues apace. Consequently, while in the winter half year, transients overwhelm the mean flow moisture divergence and $P-E$ is positive; in the summer half year, the mean flow moisture divergence dominates and $P-E$ is negative.

- This essential feature of Mediterranean hydroclimate is well represented in the multimodel mean of the CMIP5 global climate models. The calculated winter half-year transient eddy moisture flux convergence is weaker than that observed (as estimated within ERAInterim), but this might simply be because of the use of daily model data as opposed to higher temporal 
CMIP5, (1979-2005) climatology (color), (2021-2040) - (1979-2005) (contour), $\overline{\mathbf{v}^{\prime 2}}$

NDJFMA $700 \mathrm{mb}$

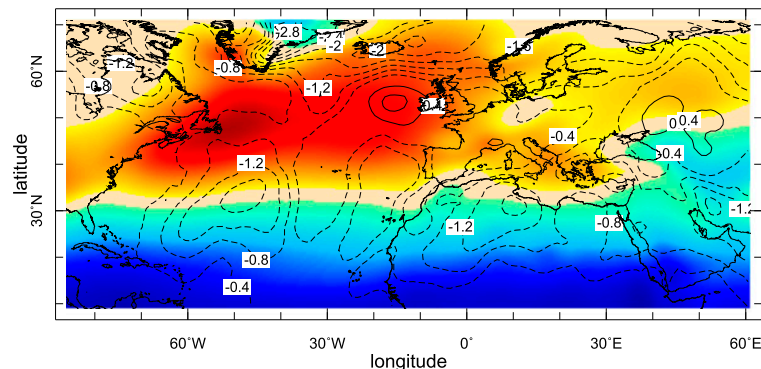

70000. $\mathrm{Pa}$

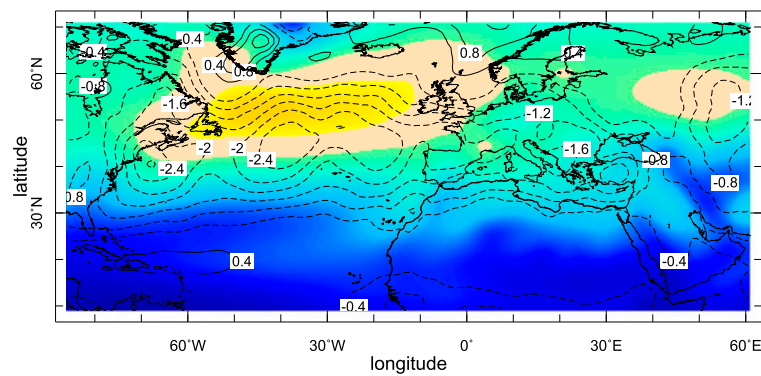

70000. $\mathrm{Pa}$

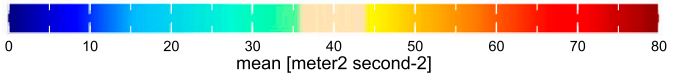

CMIP5, (1979-2005) climatology (color), (2021-2040) - (1979-2005) (contour), zg at 850mb

NDJFMA

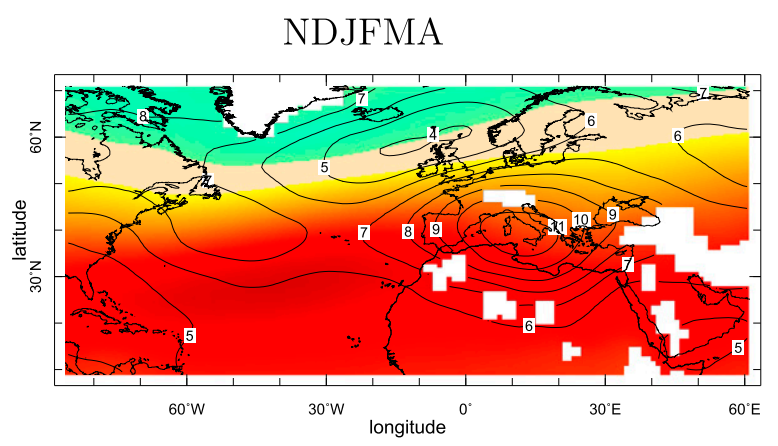

85000. $\mathrm{Pa}$
NDJFMA $250 \mathrm{mb}$

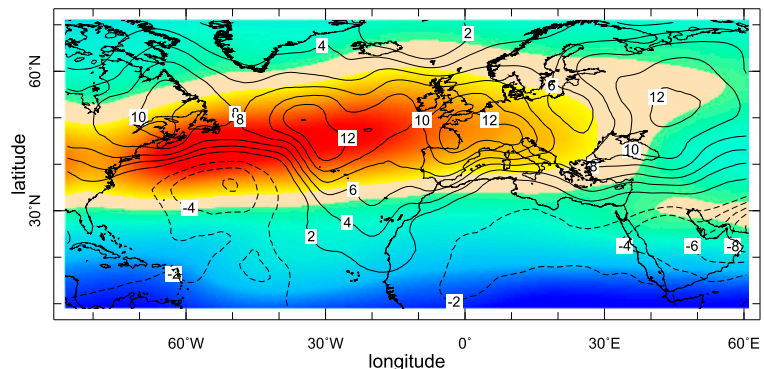

25000. Pa MJJASO $250 \mathrm{mb}$

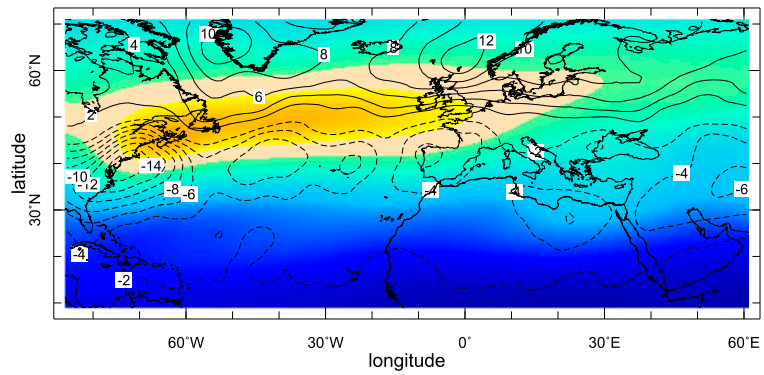

25000. $\mathrm{Pa}$

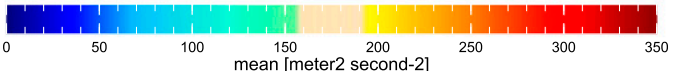

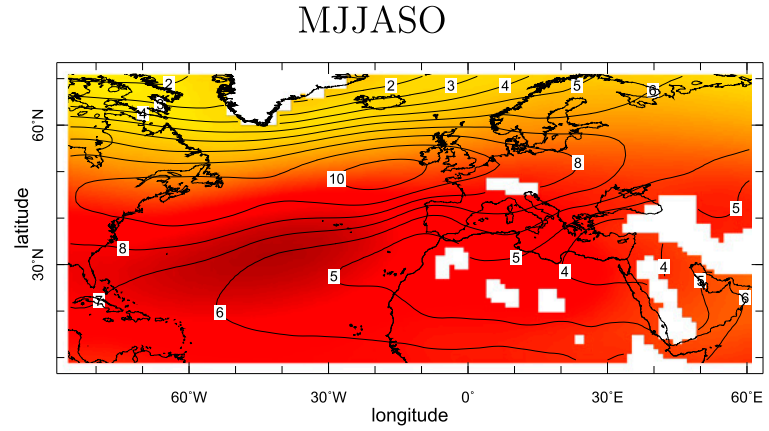

85000. $\mathrm{Pa}$

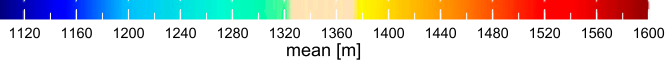

FIG. 10. The 1979-2005 climatology (colors) and change from then to 2021-40 (contours) of the multimodel mean submonthly meridional velocity variance at (top left) 700 and (top right) $250 \mathrm{mb}$ for the winter half year and the 850-mb geopotential height for the (bottom left) winter and (bottom right) summer half years. Units are $\mathrm{m}^{2} \mathrm{~s}^{-2}$ for velocity variance and meters for heights.

resolution data that better resolve covariances between the flow and humidity fields.

- Model projections for the 2021-40 period relative to the 1979-2005 period show widespread reductions in $P$ and $P-E$ across the Mediterranean region in both half years. Even though it is transient eddy moisture flux convergence that sustains positive $P-E$ over Mediterranean land regions in winter, the drying does not occur, in general, because of a reduction of the transient eddy moisture convergence. Indeed, this actually increases modestly over Spain, France, 


$$
\text { CMIP5, (2021-2040) - (1979-2005) (color and contour), } \frac{1}{g} \sum_{k=1}^{K} \Delta \bar{q}_{k} \overline{d p}_{k}
$$
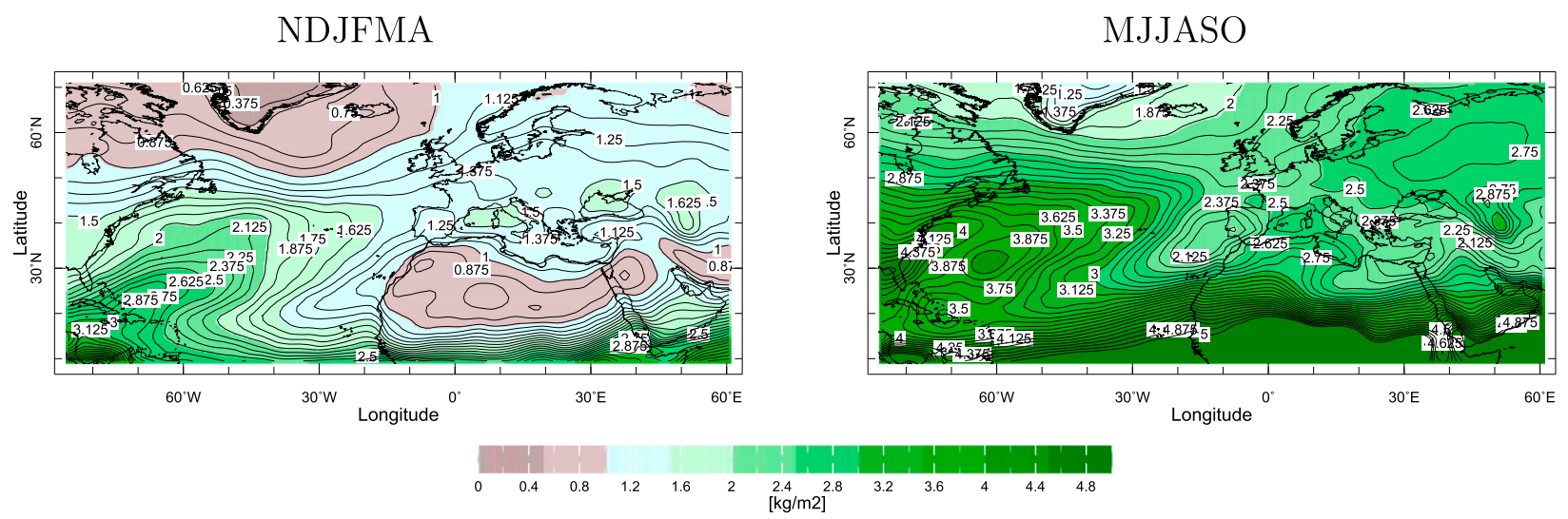

FIG. 11. The 1979-2005 to 2021-40 change in the multimodel mean surface to 600-mb vertically integrated specific humidity for the winter and summer half years. Units are kilograms per square meter.

Turkey, and the Middle East. Instead, it is an increase in the opposing mean flow moisture divergence that provides the drying tendency. In the summer half year, the mean flow moisture divergence, which in the 1979-2005 period provides for negative summer $P-E$, intensifies, making the aridification a year-round phenomenon.

- The drying due to increased mean flow moisture divergence is largely accounted for by a mean flow mass divergence anomaly that is year-round. This is related to development of a low-level high anomaly seen as a bull's-eye feature over the Mediterranean region in the winter half year, with subsidence and low-level mass divergence centered over the eastern Mediterranean and a large-scale high anomaly over the Atlantic Ocean and Northern Europe in summer that brings subsidence and low-level mass divergence to most of the Mediterranean region.

\section{b. Discussion}

Aridification of the Mediterranean region in the current century has been projected by climate models for over a decade now and remains a feature of the latest generation of climate models participating in CMIP5. However, these are global climate models that cannot easily simulate details of the precipitation distribution across the Mediterranean region. Application of the model projections in efforts to determine how to adapt to climate change would be better aided by projections performed by models that can capture realistically the complex topography and precipitation distribution of the region. Regional climate models might be useful in this regard since they are run at higher spatial resolution and have been of use in European and Mediterranean region climate projections (e.g., Kjellstrom et al. 2010). On the other hand, caution needs to be taken because regional models prevent coupling between regional-in this case Mediterraneanclimate and the global climate system, whose thermodynamical and dynamical adjustments to rising greenhouse gases are driving the more local climate change.

The hydroclimate consequences of warming and the associated thermodynamical adjustments of the hydrological cycle are well understood. The dynamical mechanisms for hydroclimate change-why the atmospheric mean and transient circulations change in the way they do-are not so well understood. It has been known for a while that the midlatitude jets and storm tracks shift poleward under global warming and the Hadley cell expands, causing expansion of subtropical dry zones (Yin 2005; Lu et al. 2007; Previdi and Liepert 2007). Wu et al. $(2012,2013)$ provide a review of proposed mechanisms for this and advance the case that this is a tropospheric response to stratospheric circulation adjustment with the signal propagating downward via linear wave refraction. However, while some analyses have shown that the jet changes vary by longitude and season (Lorenz and DeWeaver 2007), arguments for why this is so have been lagging behind explanations of the zonal mean changes.

The Mediterranean region is one location where the strength of the response cannot be easily explained in terms of zonally and seasonally invariant processes, as emphasized by Simpson et al. (2014) in a recent analysis of changes in midlatitude circulation projected by CMIP5 models. Instead, some combination of responses to rising 
greenhouse gases is causing subsidence and low-level divergence to increasingly dominate the region yearround and leading to progressive aridification that, by the already worrying standards of general subtropical drying and expansion, is quite alarming. While a reduction in transient eddy moisture flux convergence is not the cause of aridification, it is quite likely that transient eddy momentum fluxes play an important role in the mean flow circulation adjustment that does cause it. Research should be focused on why modeled atmospheric dynamics pick out the Mediterranean region to be a "hot spot"-and dry spot—of global climate change and whether they adequately represent the important physics. That said, essentially no model predicts that rising GHGs will cause the Mediterranean region to get wetter as a consequence of rising GHGs, so, instead of waiting for yet more model confirmation of what we already know, the time is ripe for Mediterranean countries to plan for the drier times ahead (e.g., Iglesias et al. 2007).

Acknowledgments. This work was supported by NOAA Award NA10OAR4310137 (Global Decadal Hydroclimate Variability and Change) and DOE Award DESC0005107. We thank Dong Eun Lee for downloading the ERA-Interim data and the European Centre for MediumRange Weather Forecasts for making the reanalysis data available. We acknowledge the World Climate Research Programme's Working Group on Coupled Modelling, which is responsible for CMIP, and we thank the climate modeling groups (listed in Table 1 of this paper) for producing and making available their model output. For CMIP the U.S. Department of Energy's Program for Climate Model Diagnosis and Intercomparison provides coordinating support and led development of software infrastructure in partnership with the Global Organization for Earth System Science Portals. We thank three anonymous reviewers for their careful and insightful reviews.

\section{APPENDIX}

\section{Model Moisture Budget Closure Errors}

As shown in $\mathrm{SH}$, diagnostic computation of moisture budgets introduces considerable error. Here we show that, despite this, analysis of the change in the moisture budget from one period to another within models, as done here, can yield useful results. The moisture budget for the twentieth- and twenty-first-century periods can be written schematically as

$$
\begin{aligned}
& (P-E)_{20}=-\mathrm{MC}_{20}-\mathrm{TE}_{20}+R_{20} \text { and } \\
& (P-E)_{21}=-\mathrm{MC}_{21}-\mathrm{TE}_{21}+R_{21},
\end{aligned}
$$

where $\mathrm{MC}$ and TE represent the divergence of vertically integrated moisture flux by the mean flow and transient eddies, respectively [as in Eq. (3)], and $R$ represents the residual error in the calculation within the models. The time tendency of vertically integrated moisture is neglected here as this is small compared to the error of the half-year calculations presented here. The top two panels of Fig. A1 show the summer and winter half years maps of $R_{20}$ for the CMIP5 models for the 1979-2005 period using the same color scale as that for the climatological maps of the models budgets in the main body of the paper. This pattern is very similar to that of the models' divergence of vertically integrated moisture flux (Figs. 3 and 4) and is a sign that, if TE was of larger amplitude, the error in the balance would be smaller. That is a clear indication that the prime source of error in the climatological balance arises from using daily means rather than 6 hourly data in the calculations, a choice made based on data availability and the need to include as many models in the multimodel mean for the same time periods as possible. This is consistent with what was found by $\mathrm{SH}$.

The difference in the moisture budget for 2021-40 relative to $1979-2005$ is given by

$$
\Delta(P-E)=-\Delta(\mathrm{MC})-\Delta(\mathrm{TE})+\Delta R,
$$

which is the same as Eq. (6). The lower two panels of Fig. A1 show $\Delta R$ for the two half years. These panels use a color scale that is an order of magnitude narrower than for the climatological case as in the main paper. The error in the moisture budget change is not only much smaller than the error in the climatological budget but also does not have the same systematic character that the climatological error does. This is because the error in the budget introduced by the underestimation of TE using daily means is about the same for the two time periods and largely disappears upon taking the difference. Instead the error in the moisture budget change is less spatially coherent and does not disrupt the regionalscale patterns of drying and moistening that are the main focus of this paper. However, it should be noted that the errors are sufficiently large that definitive assessments of the causes of hydroclimate change and the mechanisms responsible are hard to make. Had 6 hourly data been available for all the models, then the error in the moisture budget change would have been smaller; based on $\mathrm{SH}$, however, it is unlikely to have gone away. A more accurate calculation might also lead to changes in the relative quantitative influence of the different moisture budget terms. At this point in the climate modeling endeavor, this level of error must be accepted. However, as shown here, the error does not reach a magnitude that 


\section{CMIP5 Moisture Budget errors}

[1979-2005]
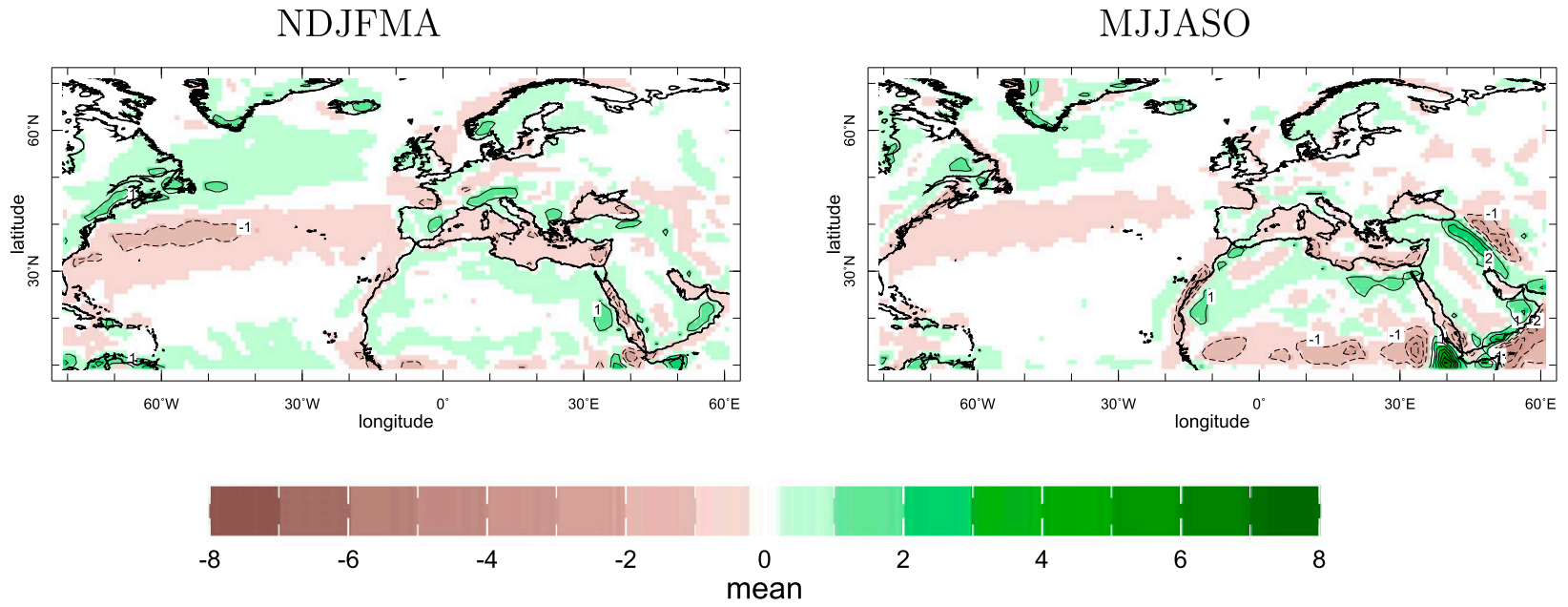

[2021-2040] - [1979-2005]
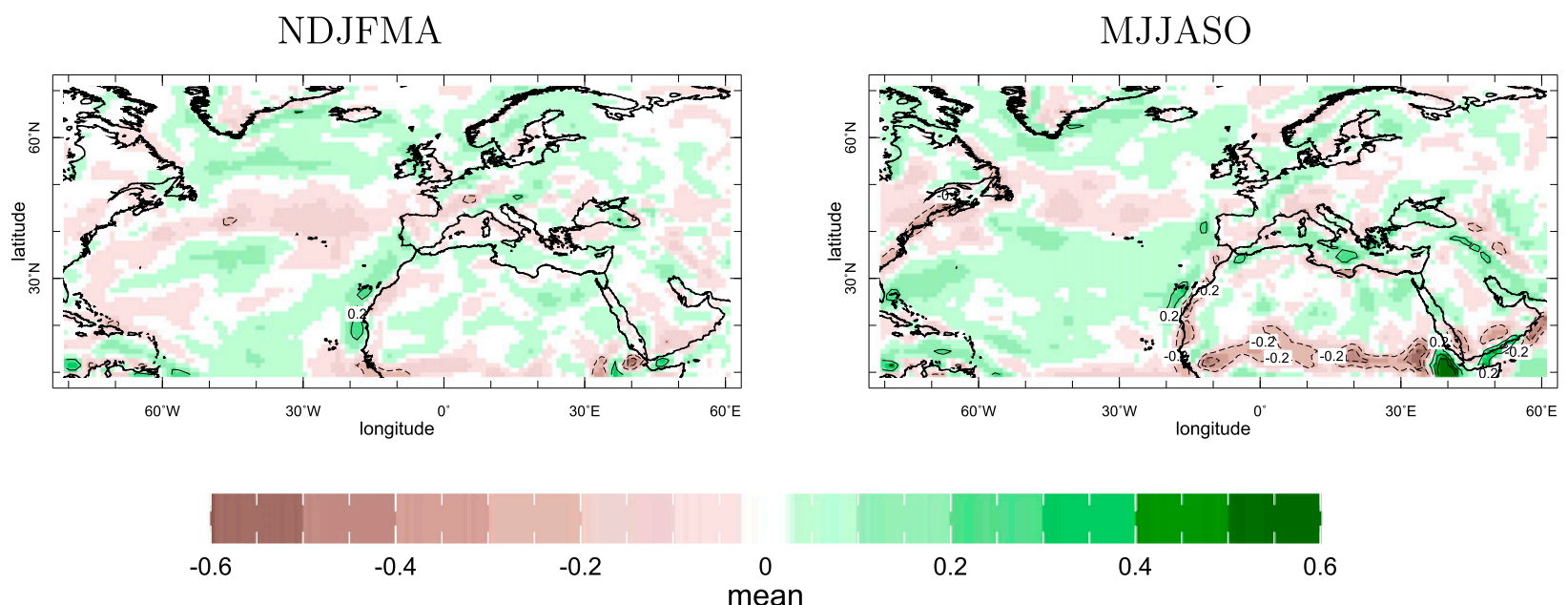

FIG. A1. The error (imbalance between the divergence of vertically integrated moisture transport and $P-E$ ) for (top) the climatological moisture budget and (bottom) the twentieth- to twenty-first-century change in moisture budget, shown for winter and summer half years. Note the difference in color scales for the climatology and the change. Units are millimeters per day.

would justify inaction on the part of workers aiming to use the CMIP5 model data to understand projections of hydroclimate change.

\section{REFERENCES}

Allen, M. R., and W. J. Ingram, 2002: Constraints on future changes in climate and the hydrologic cycle. Nature, 419, 224-232, doi:10.1038/nature01092.
Berrisford, P., P. Kallberg, S. Kobayashi, D. Dee, S. Uppala, A. J. Simmons, P. Poli, and H. Sato, 2011a: Atmospheric conservation properties in ERA-Interim. Quart. J. Roy. Meteor. Soc., 137, 1381-1399, doi:10.1002/qj.864.

— , and Coauthors, 2011b: The ERA-Interim archive version 2.0. European Centre for Medium-Range Weather Forecasts ERA Tech. Rep. 1, 23 pp.

Chang, E. K. M., S. Lee, and K. L. Swanson, 2002: Storm track dynamics. J. Climate, 15, 2163-2183, doi:10.1175/ 1520-0442(2002)015<02163:STD>2.0.CO;2. 
—, Y. Guo, and X. Xia, 2012: CMIP5 multimodel ensemble projection of storm track change under global warming. J. Geophys. Res., 117, D23118, doi:10.1029/2012JD018578.

Chanson, H., 2008: The hydraulics of Roman aqueducts: What do we know? Why should we learn? Proc. World Environmental and Water Resources Congress, Honolulu, HI, Amer. Soc. Civ. Eng., 1-16.

Chou, C., J. D. Neelin, C. Chen, and J. Tu, 2009: Evaluating the "rich-get-richer" mechanism in tropical precipitation change under global warming. J. Climate, 22, 1982-2005, doi:10.1175/ 2008JCLI2471.1.

Cubasch, U., and Coauthors, 2001: Projections of future climate change. Climate Change 2001: The Scientific Basis, J. T. Houghton et al., Eds., Cambridge University Press, 525582.

Dee, D., and Coauthors, 2011: The ERA-Interim reanalysis; Configuration and performance of the data assimilation system. Quart. J. Roy. Meteor. Soc., 137, 553-597, doi:10.1002/ qj.828.

Essex, S., M. Kent, and R. Newnham, 2004: Tourism development in Mallorca: Is water supply a constraint? J. Sustainable Tourism, 12, 4-28, doi:10.1080/09669580408667222.

Giorgi, F., 2006: Climate change hot-spots. Geophys. Res. Lett., 33, L08707, doi:10.1029/2006GL025734.

- , and E. Coppola, 2007: European climate-change oscillation. Geophys. Res. Lett., 34, L21703, doi:10.1029/2007GL031223.

- , and P. Lionello, 2008: Climate change projections for the Mediterranean region. Global Climate Change, 63, 90-104, doi:10.1016/j.gloplacha.2007.09.005.

Harvey, B. J., L. C. Shaffrey, T. J. Woollings, G. Zappa, and K. I. Hodges, 2012: How large are projected 21st century storm track changes? Geophys. Res. Lett., 39, L18707, doi:10.1029/ 2012 GL052873.

Held, I. M., and B. J. Soden, 2006: Robust responses of the hydrological cycle to global warming. J. Climate, 19, 5686-5699, doi:10.1175/JCLI3990.1.

Hillel, D., 1994: The Rivers of Eden: The Struggle for Water and the Quest for Peace in the Middle East. Oxford University Press, $355 \mathrm{pp}$.

Hoerling, M. P., J. Eischeid, J. Perlwitz, X. Quan, T. Zhang, and P. Pegion, 2012: On the increased frequency of Mediterranean drought. J. Climate, 25, 2146-2161, doi:10.1175/ JCLI-D-11-00296.1.

Iglesias, A., L. Garrote, F. Flores, and M. Moneo, 2007: Challenges to manage the risk of water scarcity and climate change in the Mediterranean. Water Resour. Manage., 21, 775-788, doi:10.1007/s11269-006-9111-6.

Kelley, C., M. Ting, R. Seager, and Y. Kushnir, 2011: The relative contributions of radiative forcing and internal climate variability to the late 20th century winter drying of the Mediterranean region. Climate Dyn., 38, 2001-2015, doi:10.1007/ s00382-011-1221-z

,,$-- \ldots$, and,- 2012 : Mediterranean precipitation climatology, seasonal cycle, and trend as simulated by CMIP5. Geophys. Res. Lett., 39, L21703, doi:10.1029/ 2012 GL053416.

Kjellstrom, E., G. Nikulin, U. Hansson, G. Strandberg, and A. Ullerstig, 2010: 21st century changes in the European climate: Uncertainties derived from an ensemble of regional climate model simulations. Tellus, 63A, 24-40, doi:10.1111/ j.1600-0870.2010.00475.x.

Lionello, P., and F. Giorgi, 2007: Winter precipitation and cyclones in the Mediterranean region: Future climate scenarios in a regional simulation. Adv. Geosci., 12, 153-158, doi:10.5194/ adgeo-12-153-2007.

Lorenz, D. J., and E. T. DeWeaver, 2007: Tropopause height and the zonal wind response to global warming in the IPCC scenario integrations. J. Geophys. Res., 112, D10119, doi:10.1029/ 2006JD008087.

Lu, J., G. Vecchi, and T. Reichler, 2007: Expansion of the Hadley cell under global warming. Geophys. Res. Lett., 34, L06805, doi:10.1029/2006GL028443.

Mariotti, A., M. V. Struglia, N. Zeng, and K. Lau, 2002: The hydrological cycle in the Mediterranean region and implications for the water budget of the Mediterranean Sea. J. Climate, 15, 1674-1690, doi:10.1175/1520-0442(2002)015<1674: THCITM $>2.0 . \mathrm{CO} ; 2$.

, N. Zeng, J.-H. Yoon, V. Artale, A. Navarra, P. Alpert, and L. Z. X. Li, 2009: Mediterranean water cycle changes: Transition to drier 21st century conditions in observations and CMIP3 simulations. Environ. Res. Lett., 3, 044001, doi:10.1088/1748-9326/3/4/044001.

Mays, L. W., 2010: A brief history of water technology during antiquity: Before the Romans. Ancient Water Technologies, L. W. Mays, Ed., Springer Dordrecht, 1-28.

Planton, S., and Coauthors, 2012: The climate of the Mediterranean region in future climate projections. The Climate of the Mediterranean Region, P. Lionello, Ed., Elsevier, 449-502.

Previdi, M., and B. Liepert, 2007: Annular modes and Hadley cell expansion under global warming. Geophys. Res. Lett., 34, L22701, doi:10.1029/2007GL031243.

Riahi, K., and Coauthors, 2011: RCP 8.5-A scenario of comparatively high greenhouse gas emissions. Climatic Change, 109, 33-57, doi:10.1007/s10584-011-0149-y.

Schwartz, F. W., and M. Ibaraki, 2011: Groundwater: A resource in decline. Elements, 7, 175-179, doi:10.2113/ gselements.7.3.175.

Seager, R., and N. Henderson, 2013: Diagnostic computation of moisture budgets in the ERA-Interim reanalysis with reference to analysis of CMIP-archived atmospheric model data. J. Climate, 26, 7876-7901, doi:10.1175/JCLI-D-13-00018.1.

, N. Naik, and G. A. Vecchi, 2010: Thermodynamic and dynamic mechanisms for large-scale changes in the hydrological cycle in response to global warming. J. Climate, 23, 4651-4668, doi:10.1175/2010JCLI3655.1.

-, , and L. Vogel, 2012: Does global warming cause intensified interannual hydroclimate variability? J. Climate, 25, 3355-3372, doi:10.1175/JCLI-D-11-00363.1.

Simpson, I. R., T. A. Shaw, and R. Seager, 2014: A diagnosis of the seasonally and longitudinally varying midlatitude circulation response to global warming. J. Atmos. Sci., doi:10.1175/ JAS-D-13-0325.1, in press.

Stocker, T. F., and Coauthors, 2013: Climate Change 2013: The Physical Science Basis. Cambridge University Press, 1535 pp. [Available online at www.climatechange2013.org/images/report/ WG1AR5_ALL_FINAL.pdf.]

Taylor, K. E., R. J. Stouffer, and G. A. Meehl, 2012: An overview of CMIP5 and the experiment design. Bull. Amer. Meteor. Soc., 93, 485-498, doi:10.1175/BAMS-D-11-00094.1.

Trigo, I. F., T. D. Davies, and G. R. Bigg, 2000: Decline in Mediterranean rainfall caused by weakening of Mediterranean cyclones. Geophys. Res. Lett., 27, 2913-2916, doi:10.1029/ 2000GL011526.

Wu, Y., R. Seager, M. Ting, N. Naik, and T. Shaw, 2012: Atmospheric circulation response to an instantaneous doubling of 
carbon dioxide. Part I: Model experiments and transient thermal response in the troposphere. J. Climate, 25, 28622879, doi:10.1175/JCLI-D-11-00284.1.

,,,--- , and,- 2013: Atmospheric circulation response to an instantaneous doubling of carbon dioxide. Part II: Atmospheric transient adjustment and its dynamics. J. Climate, 26, 918-935, doi:10.1175/JCLI-D-12-00104.1.

Yin, J. H., 2005: A consistent poleward shift of the storm tracks in simulations of 21st century climate. Geophys. Res. Lett., 32, L18701, doi:10.1029/2005GL023684.
Zappa, G., L. C. Shaffrey, K. I. Hodges, P. G. Sansom, and D. B. Stephenson, 2013: A multimodel assessment of future projections of North Atlantic and European extratropical cyclones in the CMIP5 climate models. J. Climate, 26, 5846-5862, doi:10.1175/JCLI-D-12-00573.1.

Ziv, B., Y. Kushnir, J. Nakamura, N. H. Naik, and T. Harpaz, 2013: Coupled climate model simulations of Mediterranean winter cyclones and large-scale flow patterns. Nat. Hazards Earth Syst. Sci., 13, 779-793, doi:10.5194/ nhess-13-779-2013. 